University of Rhode Island

DigitalCommons@URI

Open Access Dissertations

1994

\title{
A Longitudinal Study of the Effects of Education on Decision- Making and Satisfaction in Re-Entry Women's Intimate Relationships
}

Carolyn Cobb Celebucki

University of Rhode Island

Follow this and additional works at: https://digitalcommons.uri.edu/oa_diss

\section{Recommended Citation}

Celebucki, Carolyn Cobb, "A Longitudinal Study of the Effects of Education on Decision-Making and Satisfaction in Re-Entry Women's Intimate Relationships" (1994). Open Access Dissertations. Paper 965. https://digitalcommons.uri.edu/oa_diss/965

This Dissertation is brought to you for free and open access by DigitalCommons@URI. It has been accepted for inclusion in Open Access Dissertations by an authorized administrator of DigitalCommons@URI. For more information, please contact digitalcommons-group@uri.edu. 


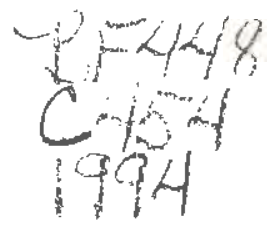

A LONGITUDINAL STUDY OF THE EFFECTS OF EDUCATION ON DECISION-MAKING AND SATISFACTION

IN RE-ENTRY WOMEN'S

INTIMATE RELATIONSHIPS

BY

CAROLYN COBB CELEBUCKI

A DISSERTATION SUBMITTED IN PARTIAL FULFILLMENT OF THE REQUIREMENTS FOR THE DEGREE OF

DOCTOR OF PHILOSOPHY

IN

PSYCHOLOGY

UNIVERSITY OF RHODE ISLAND

$$
\because 2+1+2+2
$$


A longitudinal study, that assessed the effects of changes in education on changes in decision-making and satisfaction in ongoing intimate relationships, was conducted with 78 women re-entry students who, as matriculants in an undergraduate degree granting program in the College of Continuing Education at URI in Providence in 1988, participated in this study at Time 1 and again three and one half years later at Time 2 . Three measures each of decisionmaking, satisfaction, and perceived partner support for their education, and two measures of education were obtained. Women reported on demographic information i.e., age, sex, income, employment status, and children in household, for themselves and their partners, as well as educational barriers, recent life experiences, and type (cohabiting, married), duration, and stability of their relationships.

Within subjects repeated measures were analyzed using SPSSX MANOVA. Pearson and partial correlations and ANOVAs were also conducted. As predicted, with the effect of change in income controlled, women who increased their education level, reported both increased decision-making and increased relationship satisfaction, and changes in decision-making were positively correlated with changes in satisfaction. As predicted, changes in relationship satisfaction and changes in perception of partner's support for their education were positively correlated. Whereas change in partner's income was correlated with change in relationship satisfaction, only for women who had not yet completed their undergraduate degree, change in the relative income between the participant and her partner was correlated with changes in relationship satisfaction for all women. Furthermore, as predicted, women with higher incomes at Time 2 than at Time 1 did have more global decisionmaking power in their relationships provided that their partners did not have increases in income during that time period; contrary findings were obtained with moresay decision-making in this group. There was no support for the hypothesis that women with lower incomes at Time 2 than at Time 1 would have decreased in their decision-making power; however, if the income level of their partners increased from Time 1 to Time 2 while their own income did not, 
the participant's own decision-making did decrease during that period in support of the hypothesis. 


\section{Acknowledgements}

I wish to acknowledge the generous support I have received from Dean Walter Crocker of the College of Continuing Education (CCE) at the University of Rhode Island and Dr. Kathryn Quina, the director of the Psychology Department at CCE. I am thankful, not only for their interest in this longitudinal study, but for the opportunity to work as a graduate assistant with Dr. Quina at CCE for two years. The germ of this research was nurtured in this environment, which is very supportive of mature returning students, and in the the many conversations with re-entry students who "dropped by the office to chat."

I owe a great debt of gratitude to my committee members, who have been involved in this research over the past five years: Drs. Mary Ellen Reilly; Patricia Morokoff; Lisa Harlow and to my major professor, Bernice Lott, who has supported me not only in this research endeavor, but throughout my entire graduate career.

Lastly, I want to thank my family, my sisters Jean, Dorothy, and Kathryn, who have commiserated with me in my setbacks and applauded me in my victories; and my children, Daniel, Robin, Kenneth and Jill, who lived most of their lives with a mother who was "leaving for class." I could not have done it without their understanding.

My deepest thank you is reserved for my mother, who believed I could do anything, and for my father who loved me even when I couldn't. 


\section{Table of Contents}

$\underline{\text { Page }}$

List of Tables.

$\mathrm{v} \mathbf{i}$

Chapter I: $\quad$ The Problem............................................ $1-31$

Chapter II: Method................................................... $32-41$

Chapter III: Results............................................... $42-63$

Chapter IV: Discussion............................................ $64-78$

Appendix A: Instruments,...................................... 79 - 91

Appendix B: Tables................................................. $92-108$

Bibliography.............................................................. $109-121$ 
Table 1: Time 1 to Time Change in Decision-making, Relationship Satisfaction, Income, and Partner

Support.

Table 2: Demographic Information on Women Surveyed at Both Time 1 and Time 2

Table 3: Scores at Time 1 and Time 2 on all Decision-making, Relationship Satisfaction, Income, and Partner Support Measures

Table 4: Pearson Comelations Among All Change Scores in Decision-making, Relationship Satisfaction, Partner Support, Income, and Education and the Top Five Barriers to Education and Stress Reported at Time

Table 5: Partial Correlations (Controlling for Change in Relative Income) Between Percent of Education and Change Scores in Decision-making, Relationship Satisfaction, and Partner Support.

Table 6: Analysis of Variance in Change in Decision-making Scores as a Function of Education Status....

Table 7: Analysis of Variance in Change in Relationship Satisfaction Scores as a Function of Education Status.

Table 8: Partial Correlations (Controlling for Change in Relative Income) Between Change Scores in Decisionmaking, Relationship Satisfaction, and Partner Support.

Table 9: Pearson Correlations Between Change Scores of the Individual Items of the Predicted Say Scale and Change Scores in Decision-making, Relationship Satisfaction, Partner Support.

Table 10: Pearson Correlations Between Time 1 and Time 2 Scores on Decision-making, Relationship Satisfaction and

Partner Support.

Table 11: Repeated Measures Analyses of Variance on Decisionmaking Scores as a Function of Time.

Table 12: A Listing of Barriers to Education in Order of Frequency of Selection by Respondents

Table 13: Top 5 Barriers by Respondents Who Have Not Completed Undergraduate Degrees Grouped by Education Status at Time 2 . 
A Longitudinal Study of the Effects of Education on Decisionmaking and Relationship Satisfaction in Re-entry Women's Intimate Relationships.

Background and Statement of the Problem

The present study is concerned with the changes over a three and one-half year period in the relationships between education and perceived relationship power and relationship satisfaction among heterosexual women who were re-entry students enrolled in an undergraduate degree granting program in the fall of 1988 and were also involved at that time in an intimate cohabiting or married relationship. If expertise can affect leadership in the short term pairings of men and women in the laboratory as has been demonstrated (Fleischer \& Chertkoff, 1986), it is possible that education will have a similar effect on the relationships of longer term couples since skill and knowledge can be enhanced by education. With education comes increased recognition of competencies both in the classroom and in the larger society. Competence recognition is part of the evaluative feedback that affects self-efficacy, and level of selfefficacy affects performance (Bandura, 1982). If skill development, general and specific knowledge, and recognition of abilities are increased by education, then education may function in life just as task competence functions in the laboratory to increase the recognition of leadership (or power). While education cannot be manipulated, persons can be evaluated at 
different times in their undergraduate years and compared on their perceived levels of power in their intimate relationships.

Education is a variable of particular interest to psychologists because it is amenable to change. A society can increase the education levels of its members, can work to remove barriers to education, and can strive to increase equal opportunity. "Educational attainment is one of most important means by which to gain socioeconomic mobility and independence for women" (Cardoza, 1991, p.133). Additionally, the number of reentry women, i.e., mature women returning to school to further their education after a prolonged absence, has greatly increased in the past few decades. Although women and men were equally represented among re-entry students in the $1960 \mathrm{~s}$, in the 1970s the enrollment of women between the ages of 25-34 years in higher education increased by $187 \%$ (Quina-Holland \& Kanerian, 1983). In the 1980s, re-entry women outnumbered re-entry men by 4 to 1 (Crimmins \& Riddler, 1985). Eighty percent of the students at the College of Continuing Education (CCE) at the University of Rhode Island are women.

\section{Conceptual Framework and Review of the Literature}

Gender and Power. Social psychologists and sociologists have long been concerned with interpersonal power (Blau, 1964; French \& Raven, 1959; Thibaut \& Kelley, 1959), and feminist psychologists have been particularly interested in the dynamics of power that pertain to women's development and relationships with men (Chodorow, 1978; Henley, 1977; Johnson, 1976; Lott, 
1987; Miller, 1977). In examining power, many feminists take as a starting point the patriarchal structure of contemporary western society (Brownmiller, 1975; Miller, 1977; Rush, 1978), and generally agree with Weedon (1987) in defining patriarchy as "...power relations in which women's interests are subordinated to the interests of men. These power relations take many forms from the social organization of procreation to the internalized norms of femininity by which we live" (p. 2).

Feminist scholars are interested not only in the basis of power inequities between women and men in our society, but in ways in which this balance of power can be modified. Westkott (1979), for example, states that "the difference between a social science about women and a social science for women, between the possibilities of self-exploitation and those of liberation, is our imaginative capacity to inform our understandings of the world with a commitment to

overcoming the subordination and devaluation of women" (p.430). This "intention for the future, rather than a resignation to the present" (Westkott, p.428), has been an aspect of feminist social psychology since its beginnings.

Power, as defined by Thibaut and Kelley (1959) and Howard, Blumstein and Schwartz (1986), is inferred from "the control of resources that provide the powerholder with the potential for exercising influence, that is, for altering the behavior of others (p. 102)." The concept of power has been developed along several dimensions: referent, expert, coercive, reward, legitimate (French \& Raven, 1959); direct/indirect (Miller,1977); and 
rational/irrational (Falbo, 1977). Researchers have examined types of tactics and strategies used to gain and maintain power ( Howard, Blumstein, \& Schwartz, 1986; Rusbult, 1987) and conflict negotiation within intimate relationships (Billingham \& Sack, 1987), with power strategies defined along several parameters, i.e., weak/ strong (Kipnis, 1976), direct/indirect and rational/irrational (Falbo, 1977).

Power has been examined in the context of same-gender and mixed-gender groups (Boston \& Hoffman, 1985; Drake, 1986; Forsyth, Donelson \& Schlenker, 1985; Wood, 1986) and in social settings (Blau, 1964; Henley, 1977; Kahn, 1984; Kipnis, Castell \& Mauch, 1976), dating (Cate, Lloyd \& Henton, 1985; Koss, 1985; Lewin, 1985; Peplau, 1979; Sprecher, 1985), and intimate relationships (Bernard, 1971; Billingham \& Sack, 1987; Howard, Blumstein \& Schwartz, 1986; Huston \& Ashmore, 1986; Peplau, 1983; Peplau, Rubin, Zick \& Hill, 1977; Pleck, 1979; Reilly \& Lynch, 1987; Walker, 1979). Drake (1986) has looked at influence attempts across mixed-gender dyads while Koss (1985), Koss, Beesley and Oros (1985), Frieze (1983), Firestein (1987), and Walker (1979) have examined sexual coercion and aggression in intimate relationships. Much of this research has relied on college students in one-time-only laboratory experiments or, if power in dating or intimate relationships was examined (eg., Cate, Lloyd \& Henton, 1985; Sprecher, 1985), it was usually within short-term, non-cohabiting, non-married, college student samples. The present research examines changes in perceived power by women in longer lasting relationships. 
Empirical studies of power in laboratory situations have sometimes operationalized the concept as leadership position. Nyquist and Spence (1986), in assessing the effect of dominance (as measured by the California Personality Inventory List) on leadership position in same-gender and mixed-gender dyads, paired high and low dominant college students and found that whereas the dominant member of the pair (as measured by the personality inventory) became the leader $73 \%$ of the time in same-gender pairs, in mixed-gender pairs the dominant partner was significantly more likely to be the leader if a man (90\%) than a woman $(35 \%)$. A low dominant man when paired with a high dominant woman became the leader $65 \%$ of the time. If this low dominant man was paired with a high dominant man, he would have become the leader only $27 \%$ of the time.

When Fleischer and Chertkoff (1986) replicated this experiment, they manipulated the amount of expertise the participants were "known" to have, and this information was given to both members of the dyad. They found that when the dominant woman participant in the mixed-gender dyad was said to have high expertise, her likelihood of becoming the acknowledged leader increased to $73 \%$. This was a significant increase from the $35 \%$ chance that the high dominant woman, paired with a low dominant man, had of becoming the leader if no information was provided about specific performance-related abilities (Nyquist \& Spence, 1986). Thus, gender bias favoring men for leadership positions has been shown to be modified by concrete information about a woman's expertise. 
Both gender and status have been shown to affect the perception of leadership in a study of college students. Geis, Boston and Hoffman (1985) found that women's leadership behaviors received increased recognition by viewers of TV ads when a woman was both the experimenter and the authority figure in the stimulus material. This research suggests that under certain circumstances the perception of women as leaders (i.e., as powerful persons) can be successfully increased.

Intimate relationships. Within the last 10 years, a considerable amount of research has been done on power relationships within couples. Research comparing heterosexual cohabiting, married, gay and lesbian couples has helped to identify some of the variables that contribute to power differences between partners in intimate relationships (Cochran \& Peplau, 1985; Duffy \& Rusbult, 1986; Howard, Blumstein \& Schwartz, 1986; Peplau, 1979). Research on same-gender couples has been especially helpful in examining power dynamics in the absence of gender differences so that gender can be separated from other aspects of power in much the same way as information on task competence and self-reported leadership style was separated from gender in same and mixedgender dyads in laboratory settings. Research on lesbian couples (women in same sex intimate relationships) has generally found them to be more egalitarian in power than other types of couples (Blumstein \& Schwartz, 1983; Kurdeck, Lawrence \& Schmitt, 1986; Reilly and Lynch, 1990), suggesting the possibility of 
egalitarianism within heterosexual couples under particular, enabling circumstances.

Altrocchi and Crosby (1989) were able to isolate two distinct factors in married couples' ratings as to which partner was most associated with different tasks or role behaviors. Couples in this study were designated as either egalitarian or traditional according to the populations from which they were recruited. Egalitarian couples were recruited from faculty or graduate student couples in clinical or social psychology in a prominent private university, from couples living in a major city in which one member belonged to the National Organization of Women (NOW), or from couples who were co-leaders in a national marital enrichment organization. Traditional couples were members of fundamentalist religious denominations, or couples in which the husband worked as an independent distributor in a corporation which presents a philosophy that emphasizes distinct gender roles in marriage, e.g. "the husband initiates contact and expands the business, and the wife maintains the business by means of sales and record keeping" (Altrocchi \& Crosby, 1988, p. 643). Scores on the leadership dimension (head of the family, leadership in times of crisis, responsibility for major decisions, determines course of major events, career more important, and responsibility for earning money) successfully discriminated between the traditional and egalitarian couples.

Power distribution within couples has been examined in terms of institutional or structural factors as well as interpersonal variables. Institutional or structural factors include gender, age, 
race, ethnicity, education, income and assets. That these factors have been found to predict power has been attributed to differences in access to resources that allow for the exercise of social influence. Interpersonal variables that have been found to be related to power within couples are relative dependence, attractiveness, level of commitment to the relationship, availability of positive alternatives to the present relationship, contributions and costs of the relationship, and rewards gained in the relationships. Within heterosexual marriages, "inequalities can be attributed to differences in the resources that men and women provide to their families" (Steil \& Weltman, 1991, p. 162). Many wives have less influence because, relative to their husbands, they provide fewer outside resources (i.e., income and status) (Blood and Wolfe, 1960; Scanzoni, 1972; Thibaut and Kelly, 1959). "According to resource theory, if wives could achieve comparable positions with their husbands (especially in terms of income), then the differential valuing of careers and the unequal sharing of household responsibilities should be eradicated" (Steil \& Weltman, 1991, p. 162).

Structural and interpersonal variables are likely to overlap since couples are embedded within the larger culture, and structural inequities (e.g., in income) can affect interpersonal variables such as relative dependence. Rodman (1972) suggests that societies can be characterized on the basis of gender roles into four types: patriarchy, modified patriarchy, transitional equalitarianism and equalitarianism. In transitional equalitarian societies like the United States, the culture does not clearly 
dictate who should have the power and this makes for a "power struggle" (Rodman, 1973, p.64). In this struggle, great emphasis is placed upon the husband/father's breadwinner role, and occupational, educational and income status are positively associated with husband's power.

Cultural resource theorists argue that the resource perspective must be tempered by a number of cultural considerations.

Societal norms influence the exchange value of specific resources (e.g., the capacity to generate income is more highly valued than the capacity to nurture). Societal norms also affect the conditions under which resources will alter the distribution in marital power (Bahr, 1982; Rodman, 1972), and the relative value of seemingly equal contributions are dependent to some extent upon the cultural valuing of gender roles. For example, Steil and Weltman (1991) who studied specially matched dualcareer couples, one half of which had wives earning $1 / 3$ more than their husbands, and the remaining half having husbands earning $1 / 3$ more than their wives, found relative income (between wives and husbands) to be predictive of own career valuing, and willingness of partner to relocate to accommodate the other's career, only under one condition, where the husband made more money than the wife. High earning wives did not value their careers more, nor did low earning husbands value their careers less. Wives in both conditions were more likely than husbands to move to accommodate their partner's careers.

Falbo (1977) found among a sample of college students in dating relationships that women were more likely than men to 
list indirect, unilateral, and weak power strategies or tactics in answer to "How do you get your way when your partner doesn't do what you want?" Howard, Blumstein \& Schwartz (1986) concluded that having a partner who was male was associated with the use of indirect, unilateral, and weak power strategies in cohabiting and married couples. Aida and Falbo (1991), in a replication of the earlier Falbo study (1977), classified marriages on the basis of whether or not the partners "shared equally in the duty to provide for the family's income" and found equal partner wives were more satisfied than traditional wives, and used all power strategies (begging, demanding, manipulating, coercing, cajoling, bargaining, negotiating, threatening) less than traditional wives. Overall, both women and men who were more satisfied used fewer strategies. Perhaps if couples have egalitarian relationships, they do not need to employ as many influence strategies because the norm within the relationship has been established.

Women are more supportive of egalitarian power arrangements within relationships than men (Blumstein and Schwartz, 1983; Falbo, 1977; Fowers, 1991; Reilly \& Lynch, 1990; Steil \& Weltman, 1991). A study comparing distressed and nondistressed couples in nonclinical populations (distressed couples said they had considered divorce or separation) found that wives generally value egalitarian roles more than husbands, with distressed wives endorsing egalitarian views more strongly than non-distressed wives and husbands in general (Fowers, 1991). Husbands in this study reported greater marital satisfaction than 
wives across all analyses and evaluated their marriages more positively than wives in terms of communication, finances, children and parenting, family and friends, and partner's personality.

Whisman and Jacobson (1989) found that, among both women and men, relationship satisfaction scores were directly related to the degree of task sharing within the relationship. "What remains to be seen is if power and/or task inequalities within given couples result in lowered satisfaction for the less powerful spouse" (p.219). The present study tests the proposition that change in power in decision-making is positively correlated with, and antecedent to, change in relationship satisfaction.

Education has been shown to be related to power balance in intimate relationships. Caldwell and Peplau (1984) found evidence in their samples of lesbian and gay couples that the partner with less education had less power in the relationship. This was not found by Reilly and Lynch (1990), but the reason for this disparity may be that while the Caldwell and Peplau sample was composed of $40 \%$ students (as opposed to fewer than $10 \%$ students in the Reilly and Lynch sample), $74 \%$ of those surveyed by Reilly and Lynch had one or more college degrees and were thus more homogeneous with respect to education. Blumstein and Schwartz (1983) found education to be related to power in all couples. Fowers (1991) found that couples with similar educational background more strongly endorsed egalitarian roles than couples with dissimilar educational backgrounds. Wives with more education than their husbands 
had higher endorsement of egalitarianism than their husbands, but if husbands had more education than their wives, both indicated lowered desire for equality in roles.

Two power scales, "More-say" and "Final-say", were used in a study that preceded the one described here (Celebucki, 1990). Re-entry women in undergraduate degree-granting programs were asked to rate their decision-making in an intimate relationship in the areas of finances, recreation, religion, affection, friends, sex, conventionality (correct and proper behavior), inlaws, time spent together, household tasks, leisure time activities, where to live, where to go on vacation, career decisions, and employment. Some of these items fall into areas of responsibility traditionally ascribed to women or men, and are not necessarily equal in importance to respondents (Fowers, 1991). Results of the first study (Celebucki, 1990), suggested that the decision-making power among more highly educated women in areas that are stereotypically feminine (i.e., matters of conventionality or proper behavior, religion, and household tasks) was less than among women with less education.

Decision-making power in matters of employment, career decision, and time spent together (stereotypically masculine areas) was somewhat greater among more educated women, as was control over one's own life or resources, i.e., decision-making power regarding friends, leisure-time activities, and affection. There was a non-significant trend in the global measure of "More-Say", with women at higher education levels perceiving 
themselves to have more overall "say" in their relationships than women with less education.

Re-entry Women. Women report that they return to school to increase their knowledge and to enhance their career possibilities. Re-entry women also report that they were unable to enter college at the traditional age, or had to leave college before completion of a degree, due to family and employment responsibilities, role demands and child related variables, selfimage problems, family of origin difficulties, and inadequate finances (Erdwins \& Mellinger, 1986; Freilino \& Hummel, 1985; Hildreth \& Dillworth, 1983; Mohney \& Anderson, 1988; Sewall, 1984). Re-entry students are motivated by a variety of needs: competency-based (skill development); security-based (a need to take care of oneself); intrinsic (fulfilling a desire); as well as career/job development (Mohney \& Anderson, 1988). Eight distinct motives for returning to school were identified by Clayton \& Smith (1987): self-improvement, self-actualization, vocational advancement, reexamination of roles and responsibilities, enhancement of family economic status, social needs, humanitarian values, and increased knowledge about the world and life.

Richter and Witten (1984) surveyed a sample of re-entry students and found lack of time to be the most serious problem they encountered in returning to school. Meers and Gilkison (1985) reported that constraints of time, money, family responsibilities and distance to campus were major reasons for attrition among re-entry women. Chagnon, Cohen, and Strover 
(1986) report that domestic labor, defined as cooking, cleaning, or doing other domestic work had a sharp negative impact on degree completion for Hispanic women. Married women spent three times as many hours on domestic labor as did single women and women with children spent four times as many hours as women without children.

Trends in the contributions of women and men to household and employment tasks from 1967 to 1987 show that within the two-parent, two-child family, committed time has remained the same for women and men over the last 20 years, but women's paid work time has increased by 11 hours per week (Zick \& McCullough, 1991). This study placed education in committed time, which also included volunteer activities, church, and extended family interactions. Family work and paid employment were not included in this category. Although there has been a decrease in leisure time for both women and men in families with children in the home, women's increased paid work and family time ( 8 hrs.) is significantly higher than men's increase in paid work and family time (3.5 hrs.).

Fifty-five percent of a sample of re-entry women queried by Quina-Holland and Kanarian in 1980, and $91 \%$ of a sample surveyed by Celebucki 9 years later, were employed outside of the home, and $82 \%$ and $62 \%$, respectively, had children living in the household. Additionally, 78\% of the those surveyed by Quina and Kanarian (1983) were responsible for the majority of household management tasks. This figure did not vary by 
number of children or whether or not the woman held an outside job, and did not vary by years in school or age.

A woman and man returning to school might both have conflicts between student role and spousal role (Gerson, 1985; Hooper, 1979; Ostrow, Paul, Dark \& Behrman, 1986), but the student role might be more congruent with the provider role associated with the man (Bernard, 1981; Pleck, 1979) than with the nurturing role associated with the woman (Deux \& Major, 1987; Gilligan, 1979). It is also probable that the spousal role is different for a woman or a man, as is the parent role (Blumstein \& Schwartz, 1983; Dion, 1985; Pleck, 1979; Spence et al, 1985). Re-entry women students, then, may be especially in need of support, since although men who are returning students may experience increased demands due to school responsibilities, they are usually not as responsible for family work (Pleck, 1979; Quina-Holland \& Kanarian, 1983), the care and maintenance of the home environment, and the nurturing of immediate and extended family members (Bernard, 1971; Blumstein \& Schwartz, 1983; Gerson, 1985; Gilligan, 1979; Kessler et al, 1985; Vanfossen, 1981; Zick \& McCullough, 1991).

When Ostrow, Paul, Dark, and Behrman (1986), asked college students in which of 10 areas they had experienced stress since the beginning of the academic year (work, academic and financial difficulties, residence and school transitions, health problems, family and relationship conflicts, relationship terminations, death of someone close), women and men differed significantly (40\% and $32 \%$, respectively) on reporting 
relationship and family conflicts, and relationship terminations. Family conflict and relationship termination were the most important predictors of adjustment to school, but financial difficulties were the most commonly reported $(48 \%)$. While up to $75 \%$ of women re-entry students are employed, more women than men students report reliance on their spouses for financial support (Ostrow, Paul, Dark and Behrman, 1986). Gerson (1985) found family income to be negatively related to self- reported role strain (defined as not enough time and conflicting demands) among re-entry students.

The majority of re-entry women students work outside the home (Celebucki, 1990; Ostrow et al, 1986; Quina-Holland \& Kanarian, 1983) and thus tend to occupy more roles than their male counterparts. In the previously mentioned research by the author (Celebucki 1990), of the 91\% of re-entry women employed outside of the home, $64 \%$ worked full-time, and $36 \%$ worked part-time. It is notable that only $16 \%$ attended school full-time. After examination of college students' attitudes towards family and work roles, Gilbert (1991) states "although increasing numbers of men assume their spouse will work, men are far less likely to consider how their spouses' employment and the realities of children will affect their plans" (p.119).

The norms for power within heterosexual relationships may also be in transition from a patriarchal to more egalitarian division between the sexes. In 1977, Safilios-Rothschild wrote: "A considerable number of American women in their 30s, 40s, and even $50 \mathrm{~s}$ are experiencing the problems that go along with 
the current social changes. Many are trying to redefine their lives in terms of new insights about themselves in a world in which they have traditionally been second class citizens. Some of them, after ten or fifteen or more years of traditional marriage have tried to renegotiate their marriage contracts so that the loving-sexual relationship with their husbands would not interfere but instead facilitate their development and selfactualization. Many have failed. Those who have succeeded attribute their success to the fact that their husbands loved them very much, and were willing to undergo possibly painful psychological changes that led to a redefinition of the relationship" (p.102). Maples (1985), discussing dual career couples in 1982, concluded: "The attitude of many women, even today, is one of sincere gratitude to their husbands for not only allowing then to pursue their own careers but encouraging them to do so. This attitude implies that the American 'macho' belief is seldom very far below the surface of most people's thinking" (p. 96). Similar sentiments have been expressed by re-entry women (Celebucki, 1990) who are thankful that their husbands "let them go to school", even though many women are working in paid jobs to actually finance their courses.

By pursuing an education, the re-entry woman is altering the status quo between herself and her partner. Less than half of the partners of the re-entry women surveyed by this author had completed a 4-year college degree, suggesting the possibility of a period of conflict after her return to higher education. Although most of the re-entry women surveyed by Celebucki (1990) were 
in relationships at that time, almost $20 \%$ were not. The information on partners of re-entry women, while sparse (Hooper, 1979; Houston-Homburg \& Strange, 1986; Vanfossen, 1986), documents some conflict. Hooper (1979) examined the satisfaction and anxiety levels of 24 husbands of women returning to school and identified three different groups of men. One group of participants (6 of 24) was highly supportive of their wives in word and deed; a second group (6 of 24) was verbally supportive only, with the wife and older children taking on the household responsibilities; and the remaining 50\% (12 of 24) felt pressured by wife and family to take on more responsibilities but did not do so. This third group reported the most conflict, and had not negotiated a more egalitarian basis of household responsibility, nor had both partners agreed to continue the previous pattern of the wife assuming complete responsibility for household duties. This last group of husbands voiced the most concern over whether or not their marriages would survive. Hooper suggested that conflicts over the wife's schooling is just one manifestation of overall conflict in the relationship.

There is a growing body of research indicating that multiple roles are health-enhancing in terms of increased opportunities for both monetary and nonmonetary rewards (Thoits, 1983; Verbrugge, 1983, 1985). It has been argued that gender-specific roles, particularly the negative aspects of marital roles, account for sex differences in problems such as depression (Aneshensel, 1986; Gove, 1972; Gove \& Tudor, 1973; Vanfossen, 1986). 
"According to this social role theory, as the traditional female role of homemaker becomes increasingly undemanding, undervalued, and frustrating, women who have only one major source of reinforcement (i.e., the family) are at high risk for developing depression since they do not have an additional role (i.e., a job) from which to gain gratification" (Whisman \& Jacobson, 1989, p. 178).

Employed women experience greater work-family conflict than employed men (Lobel, 1991), and report significantly more stressors than men (Anderson \& Leslie, 1991). Although their role overload is more of a problem for women than for men (Pleck, 1985), employed women also report higher levels of relationship satisfaction than women who do not work outside the home (Aneshensel, 1986; Safilios-Rothschild, 1970; Vanfossen, 1986). Nye (1974) compared couples in which the wives had careers, were working at lower paying jobs, or were not employed outside of the on decision-making and marital satisfaction. Although no differences were found in satisfaction between the "working" wives and the "at-home" wives, the "career" wives were found to be significantly more satisfied in their marriages than either of the other two groups. Increased stressors may be more problematic for lower paid "working" wives than for the higher paid "career" wives as the former may not be able to purchase household services. Employed wives also reported more decision-making power in their relationships than do nonemployed (at-home) wives. 
The consequences of multiple roles for re-entry women compared to full-time homemakers of the same age, background and family responsibilities were examined by Gerson (1985). Re-entry women were found to experience significantly greater positive outcomes or gratifications as well as significantly greater negative consequences, with the overall sum of outcomes positive. Gerson concluded that "The mix of positive and negative corollaries of multiple roles challenges the assumption in the literature that strain is a ubiquitous outcome. It is suggested that outcomes of multiple roles cannot be understood unless institutional arrangements supporting or challenging these role configurations are studied concurrently" (p.90).

Institutional arrangements would include those made by the school and family constellations. The College of Continuing Education (CCE) at the University Of Rhode Island in Providence is a program specifically tailored to the needs of non-traditional students. It has flexible scheduling, a performance-based admission policy, convenient locations, is primarily attended by older students, and has specific entry level classes geared to the academic competency-building and social esteem-enhancing needs of returning students. A Peer Counseling Service staffed by students provides a variety of informational and emotional supports both to the students who are assisted by the counselors, and to the counselors themselves through the training they receive.

Stress and Social Support. Women who return to school are often in a time of transition in terms of family life and leisure 
patterns (Griff, 1987; Ostrow et al, 1986). Life change is purported to result in stress to the individual (Rahe \& Ransom, 1978), and schedules of life events have been used extensively in the literature to assess stress (Cleary, 1980; Holmes \& Rahe, 1967; Horowitz et al, 1977; Sarason et al, 1978). Quina-Holland and Kanarian (1983) administered to a sample of re-entry women a Life Experience questionnaire (surveying marriage, divorce, illness, birth of a child, beginning or ending work, change in work conditions, child leaving home, inlaw troubles, major change in living conditions, etc.) based on the work of Holmes and Rahe (1967) and found that all of the events listed, with the exception of serving time in jail, had been experienced by at least one of the fifty women within the previous 5 year period.

Models of stress often measure the perceived availability of social support, and posit a negative relationship between stress and social support (Barrera, 1986; Dohrenwend et al., 1984; Felton et al., 1984; Mitchell \& Moos, 1984; Pearlin \& Schooler, 1978; Wallston et al., 1983; Wilcox 1981). Social support networks, supportive behaviors, and subjective appraisals of support (perceptions, satisfaction) are three approaches to social support conceptualization and measurement that were examined by Vaux and Harrison (1985). in their study of non-traditional women students (ages 30-61). The size (number of members) of specific networks (eg. school, work, family), the closeness of network relationships, the composition of networks, particularly the presence of a spouse, and the proportion of close friends, 
social acquaintances, and immediate family within networks, were all associated with perceptions of, and satisfaction with, support.

All but one in a sample of re-entry women interviewed by Mohney and Anderson (1988) stated that their return to college was determined by the state of their relationships and life events, and not solely by their own motivation. When re-entry women listed factors within the last 2 years that enabled them to enroll in a class, five categories emerged: lessened role demands, increased support from others, financial ability, available classes, and self-image needs, as well as "a stated intention on the part of partners to help with household tasks and childcare" (Mohney \& Anderson, 1988, p. 273).

Role partners may provide, or withhold, cognitive, emotional, and material assistance that can be used to accomplish role tasks. "The support or rejection of social network members is likely to have a critical effect on role satisfaction" (Hirsh and Rapkin, 1986, p. 237). Hirsch and Rapkin (1986) investigated the frequency and conditions under which positive and negative outcomes occur when persons occupy multiple roles, and found the strongest predictor of psychological symptomatology and overall life satisfaction for married women nurses to be the level of "work rejection of the wive's work" by their husbands.

"Marital difficulties may serve as a vulnerability factor, a precipitant, a concomitant and a consequence of depression in women" (Whisman \& Jacobson, 1989, p.178). Aneshensel (1986) examined the relationships among married women's depression, 
satisfaction and social support. Her results indicate that lack of social support and increased marital dissatisfaction precedents depressive symptoms. "Similarly high marital strain increases the odds of depression when coupled with low to moderate support, and is also associated with a perception of low support" (p. 110). Furthermore, this study found social support to have a direct positive effect on women's psychological well being, and the perception of social support to be beneficial in and of itself.

Quina-Holland and Kanarian (1983) found the majority of woman re-entry students reported feeling very supported by school friends, partners and outside friends, with support by friends at school greater than that by partner or outside friends. They reported that although $50 \%$ of the re-entry women in a married or cohabiting relationship reported shared responsibilities with their partners, behavioral indicators such as the amount of time spent on household tasks, child care, etc., did not support this conclusion. Parker, Peltier and Wolleat (1985) reported that among dual career couples it is the perceived sense of equity that is important even though in most cases women still did more homemaking tasks than men. What made the women feel fairly treated was the attitude of their spouses towards sharing responsibility. But the authors duly note that it is less likely that attitude alone will suffice as equality between the sexes becomes more and more accepted.

Income, although a resource for the provider, is considered to be tangible support for other family members. For some women in school, it is probable that higher income earned by their 
partner is a form of tangible support for their education. Partner's income was found to be correlated with relationship satisfaction for re-entry women students (Celebucki, 1990), whereas the woman's own income was not. The income levels reported by this sample suggested that the re-entry students were more similar to "working" wives than to "career" wives (Nye, 1974). Women whose partners earned the most income and women whose own earned income was the smallest were among those with the highest number of total college credits earned.

Relationship Satisfaction. Women who return to school after having postponed their college education should increase their potential for power in relationships, but the outcome of this for perceived satisfaction with the relationship could vary with other factors (Grey-Little \& Burks, 1983; Higgens, 1985; Markman, 1979; Morokoff, 1987; Pleck, 1979; Roehl \& Okein, 1984; Pond, Ryle \& Hamilton, 1963; Sands \& Richardson, 1984; Scanzoni \& Szinovacz, 1980; Spanier, 1976; Szinovacz, 1987). One possibility is that education improves the quality of intimate relationships and also personal satisfaction with the relationship. Hooper (1979) reported overall increased satisfaction and improved relationship quality among husbands of re-entry women; Pleck (1973), in a study of husbands of working wives, reported a similar finding. According to Thibaut and Kelley (1959), high and equal power should increase marital cohesiveness, one measure of marital satisfaction. Findings from the earlier cross-sectional research by the author (Celebucki, 
1990) supported the hypothesis that women at higher levels of education were more satisfied with their relationships than women with less education. Relationship power and satisfaction were shown to be modestly related overall.

Marital relationships can be evaluated in terms of both stability and satisfaction. Stability is usually determined by whether or not the relationship is still intact, no matter what the quality of the relationship. Satisfaction is the overall perceived quality of the relationship. Relationship satisfaction has been the object of study for the past 50 years, and several scales have been developed in an attempt to measure this construct (GreyLittle \& Burks, 1983; Locke \& Wallace, 1959; Markman, 1979; Roach, 1981; Spanier, 1976; Terman, 1938). National surveys have shown marital satisfaction to be the greatest contributor to overall sense of well-being or satisfaction in life (Campbell, 1980; Clayton, 1979). Marital satisfaction is usually high among newly married couples without children, declines through the child-raising years, and rises again when the children have left home (Clayton, 1979; Reiss \& Lee, 1988). One issue that remains unresolved is how to best characterize a couple's happiness since researchers often assess only one member of the couple. If both husbands and wives are assessed, aggregate measures of each are often used (Grey-Little \& Burks, 1983; Hooper, 1979; Scanzoni, 1969; Terman, 1938). Single-item global measures may be of limited value in discriminating among couples as almost all intact couples rate their marriages as very satisfying (Campbell, 1980; Celebucki, 1990; Grey-Little \& Burks, 1983). More 
complex measures of satisfaction are often confounded by the inclusion of decision-making (i.e., power) items. When couples are studied with the more complex instruments, correlations between their scores on different subscales are generally low (Grey-Little \& Burks, 1983; Reilly \& Lynch, 1990).

Resource theory (Blau, 1964; Thibaut \& Kelly, 1959) and much of the literature on marital satisfaction (Blood \& Wolfe, 1960; Fincham, 1987; Grey-Little \& Burkes, 1983) predictthat equal power will benefit marital cohesion. For couples who have negotiated the demands of multiple roles, satisfaction is high (Gerson, 1985; Hooper, 1979; Maples, 1985; Nye, 1974). Studies suggest that shared decision-making in areas considered important to the couple is most associated with satisfaction, and a lack of participation in decision-making (independence, withdrawal) or an inability to participate in decision-making (coercion, incapacitation) is associated with lower levels of satisfaction for both husbands and wives. After reviewing the literature on self-perceived and observed indicators of power and self-reported relationship satisfaction in married couples, Gray-Little and Burks (1983) concluded that high levels of satisfaction in marriage are generally associated with egalitarian power relationships. They also found evidence that marital satisfaction of wives was high in relationships where the husbands were dominant, but relationships in which husbands had coercive power over their wives were associated with the least satisfaction on the part of the wife. This latter finding was also reported by Firestein (1987) among women in dating 
relationships where the man had physically abused his partner. Gaelick, Bodenhausen and Wyler (1985) examined emotional communication and satisfaction in married couples and reported that wives' level of satisfaction was related to lack of hostility on the part of their husband (perceived as evidence of love).

Pond, Ryle and Hamilton (1963) suggest that where either husbands or wives are dominant, the satisfaction is less than when neither is dominant. Several studies reviewed by GreyLittle and Burks (1983) found marital satisfaction to be lowest in husband dominated couples (eg. Osmond \& Martin, 1978; Pond, Ryle \& Hamilton, 1963, Scanzoni, 1968), and Szinivacz (1978) found satisfaction to be lowest in gender stereotyped marriages.

Culturally supported male domination, that is, the domination of wives by husbands in societies or among classes that approve of such, may not detract from wives reported satisfaction, so long as the husband does not overstep the limits and become perceived as coercive, and as long as the wife believes in the "appropriateness" of the domination. There may also be genderspecific "agreed upon" areas of domination. Across all studies, highest satisfaction is associated with egalitarian marriages but egalitarianism may mean either joint decision making or separate-but-equal spheres of influence. Aida and Falbo (1991) classified marriages on the basis of whether or not the partners "shared equally in the duty to provide for the family's income," and found equal partners (both husbands and wives) more satisfied than traditional couples, and wives in equal marriages more satisfied than traditional wives. In comparing non- 
depressed couples with couples in which only the wife was clinically depressed, Whisman and Jacobson (1989) found both greater inequality in decision-making and greater dissatisfaction with the distribution of decision-making and household tasks among the latter. When the level of marital distress was controlled for by partialling out wives' satisfaction scores, the relationship between depression and dissatisfaction with the distribution of decision making tasks remained significant. Thus, the greater the inequality and dissatisfaction with the distribution of decision making, the greater the marital distress reported by couples in the clinical sample, and the greater the depression reported by wives in the non-clinical sample.

Hanson and Morokoff (1988) factor-analyzed 34 self-reported behaviors of married persons and identified four clusters: independence, coercion, male sex role, and finances. Independence and coercion were found to be inversely related to satisfaction in marriage, while items related to finances and male gender role (e.g., paying for restaurant check, driving) were unrelated to marital satisfaction.

Longitudinal analyses of married couples over a 3 year period reveal a gender-differentiated pattern suggesting a more complex relationship between satisfaction and marital behavior than previously shown. Problem solving interactions that were related to initial satisfaction of husbands do not necessarily relate to longterm satisfaction for couples. This was especially true of positive verbal behavior and compliance expressed by wives (Gottman \& Krokoff, 1989). While conflict engagement 
was indicative of less satisfaction in the short run, it had beneficial effects over the long run (3 years later), providing that partners, especially husbands, did not use defensiveness, stubbornness, and withdrawal from the interaction. Negativity, regardless of whether it was expressed by the husband or the wife, was associated with declines in wives', but not husbands', satisfaction. Wives of husbands who are relatively negative early in marriage become more negative themselves (Huston \& Vangelisti, 1991). In a study of married couples, negative interaction (i.e., defensiveness, stubbornness, and withdrawal from interaction) in a highly conflicted problem solving situation at Time 1 was found to be predictive of lower satisfaction three years later (Gottman \& Krokoff, 1989).

Campbell (1980) estimated the correlation between power and satisfaction from national surveys of Americans in 1957, 1971, and 1978 to be about .15. Similarly, the present author's earlier study of re-entry students found relationship power and relationship satisfaction to be moderately correlated, with correlations among measures ranging from .15 to .23 . A correlation of .22 was found between a global measure of decision-making, a single item "more-say" and a single-item global measure of satisfaction (Celebucki, 1990).

The Present Study

The present investigation is a longitudinal study of a sample of women first surveyed in 1989. The purpose of this research is to investigate the effect of change in the women's education level on their reported decision-making within ongoing intimate 
relationships, and the effects of change in education level and change in decision-making on relationship satisfaction. Re-entry women who were surveyed at Time 1 (1989) and who agreed to further participation were questioned three and one half years later at Time 2 about their education level, relationship status, decision-making, relationship satisfaction, perceived partner support for their education, income level, employment status, recent life events and barriers to education. It was hypothesized that:

1. With change in own income relative to change in partner income held constant, changes from Time 1 to Time 2 in re-entry women's education will be positively correlated with Time 1 to Time 2 changes in their decision-making in the areas of finances, recreation, affection, friends, time spent together, career and employment decisions, leisure time activities, and in overall more say;

2. With change in own income relative to change in partner income held constant, changes from Time 1 to Time 2 in re-entry women's education will be positively correlated with Time 1 to Time 2 changes in their relationship satisfaction;

3. Changes from Time 1 to Time 2 in decision-making power will be positively correlated with changes from Time 1 to Time 2 in relationship satisfaction;

4. Decision-making will be antecedent to relationship satisfaction, i.e., correlations between decision-making measured at Time 1 and relationship satisfaction measured at Time 2 will 
be greater than correlations between relationship satisfaction at Time 1 and decision-making at Time 2;

5. Women with higher self-income relative to partner's income at Time 2 than at Time 1 will report more decisionmaking at Time 2 than they did at Time 1 . Women with lower self-income relative to partner's income at Time 2 than at Time 1 will report less decision-making at Time 2 than at Time 1;

6. With change in own income controlled, changes in partner's income will be positively correlated with changes in participant's relationship satisfaction;

7. Perceived partner support for education will be positively correlated with relationship satisfaction; and

7a. Perception of negative responses of partner to educational goals will be more highly correlated with relationship satisfaction than perceived positive response of partner to educational goals. 
Method .

\section{Participants}

Responses from 78 re-entry women met all the requirements for the longitudinal study. The pool for the 1989 survey included all women matriculated in a degree granting program at the College of Continuing Education at the University of Rhode Island in the fall semester of $1988(\mathrm{~N}=608)$. The response rate for the first study was $45.9 \% \quad(\mathrm{~N}=279)$. The Time 2 sample of 219 women represents $78 \%$ of the original 279 respondents surveyed in January of 1989 who agreed to further participation in the ongoing research by furnishing an idiosyncratic identifying code and (under separate cover) their names, mailing addresses and phone numbers.

Of the 219 women who agreed to further participation, 25 were unreachable in 1992. At Time 2, 89 women responded to a mailed survey ( $45.8 \%$ response rate). Using the individual identifiers, 84 respondents were able to be matched with their Time 1 data. Responses from 6 respondents were eliminated because of large amounts of missing data., leaving 78 respondents as the final sample for all analyses. Of this final sample, 72 were reporting on the same relationship as at Time 1, 73 were currently in a relationship, and 72 were living with their partners. All but two were reporting on heterosexual relationships.

Procedure

The method of data collection at Time 2 was identical to that used at Time 1. All women were sent questionnaire packets to 
their home addresses. Each packet contained an informed consent form, the survey instruments, two stamped and addressed envelopes, and an information sheet to be returned separately if the respondent was interested in obtaining a summary of the results of the study. Respondents who were not currently involved in an intimate heterosexual relationship were requested to answer the survey questions in relation to a previous cohabiting relationship.

\section{Instruments}

All instruments used at Time 1 were readministered at Time 2 , as were some additional instruments. Instruments can be found in Appendix A.

Demographic Questionnaire. This survey requested the following demographic information: age, gender, occupation, income and education level of self and partner, employment status, duration and type of intimate sexual relationship (cohabiting/married), number of previous cohabiting/married relationships, number and ages of children living in the household, educational and vocational goals, and whether the respondent was in the same relationship as reported on at the time of the last survey (3.5 years ago) or a different one. These items are located in Appendix A, questions1-18, 20-25 and 92.

Education. Returning students, in order to fulfill specific major requirements or because of time limits on the transfer of credits, often earn more credits than the minimum of 120 for graduation. Respondents were asked to indicate the total 
number of credits earned at URI and elsewhere (item 2), the number of graduate and undergraduate credits earned in the past 3.5 years (item 108), and the number of graduate and undergraduate classes taken in the past 3.5 years (item 109). Participants were also asked to note the last semester in which they attended classes (item 110), and their current educational level, i.e., undergraduate withdrawn, undergraduate currently attending, graduate with baccalaureate degree, graduate student, or graduate degree completed (item 111).

Two measures of education were then created for use in this study. One educational level variable was computed according to participant's "educational status" at Tỉme 2 whereby $1=$ withdrawn, 2 = current undergraduate, $3=$ completion of bachelor's degrees, and $4=$ graduate school attendance. A second measure was "percentage educational progress" in terms of credits earned since Time 1. This was computed by dividing the change in total credits earned since Time 1 by the number of credits at Time 1 needed for graduation. The change in total credits variable is the difference from Time 1 to Time 2 in total credits earned at URI and elsewhere. The number of credits needed for graduation was computed by subtracting Time 1 credits earned at URI and elsewhere from 130 (a higher number than 120 since most re-entry women earn more undergraduate credits than the typical younger student).

Decision Making Measures. Three distinct measures of decision making were used: A single-item "global more say" measure (item 13) used by Falbo (1977), Howard, Blumstein and 
Schwartz (1986), and Reilly and Lynch (1990); a "final sav" decision making measure comprised of four items modified from Blood \& Wolfe (1960) i.e., money spent on entertainment, where to go on vacation, whether or not the couple moves, and whether or not you are employed (items 39 through 42); and a "more say" measure created by the author (Celebucki, 1990) using the twelve specific items of the dyadic agreement subscale of Spanier (1976). The items selected from Spanier (1976) that comprise the "more say" scale deal with the following aspects of a relationship: handling of finances, matters of recreation, religious matters, demonstrations of affection, friends, sex relations, conventionality (correct or proper behavior), ways of dealing with parents/in-laws, amount of time spent together, household tasks, leisure time interests, and career decisions. This scale includes questions 27 to 38 in Appendix A. A fourth measure "predicted say" is a composite scale created from a subset of 7 of the 12 "more say" items i.e., finances, recreation, affection, friends, time spent together, leisure time interests, career and one of the four "final say" items, i.e., who determines whether or not the participant is employed (items 27 through $31,37,38$ and 41 ).

All items were presented with the following 7 point scale: partner always (1), partner usually (2), partner somewhat more than I (3), partner and I about equally (4), I somewhat more than partner (5), I usually (6), I always (7). Mean values were used as the individual scores in all decision-making scales and these could range from 1-7 with higher scores denoting more 
reported decision-making. Single item measures could also range from 1-7 with higher scores denoting greater decisionmaking.

Allen and Strauss (1984) found the "final say" measure to be a more valid and reliable instrument than previous research had suggested and reported a stable alpha coefficient of reliability across the 5 U.S. samples studied, with 4 of the 5 showing coefficient alphas of .65 or higher. Celebucki (1990) reported a reliability of .59 for the "final say" scale. Celebucki (1990) reported a reliability of .53 for the "more say" scale.

Relationship Satisfaction Measures. Three separate measures were used. Items from the Dyadic Adjustment Scale (DAS) developed by Spanier (1976) constitute one measure of relationship satisfaction, "Spanier". This scale comprises items 60 to 91 in Appendix A. Mean scores can range from a low of 1 to a high of 6 , rather than the 0 to 5 range used by Spanier (1976). This instrument has been shown to be reliable and valid in assessing relationship adjustment. Spanier (1976), using both married and cohabiting couples, found Cronbach's alpha to be .96 for total instrument reliability. Celebucki (1990) found Cronbach's alpha to be .93 . When compared with the LockeWallace (1959) Marital Adjustment Test (MAT), an instrument widely used in research with proven sensitivity to clinical changes in marital satisfaction, the correlation with married respondents was .86 , and with divorced respondents the correlation was .88. Differences between married and divorced 
groups have been assessed with .001 level of significance with respective mean scores on the 0 to 5 scale of 3.59 and 2.19 .

A second measure of satisfaction, "Roach", is taken from the Marital Satisfaction Scale (MSS) developed by Roach (1981), and is comprised of the 6 positive and 6 negative statements with the highest inter-item correlations (range of .69 to .79). This scale is presented in Appendix A (items 48-59). Respondents used a 7 point scale to indicate extent of agreement with each item. Higher numbers indicate higher level of agreement.

Responses of $1,2,3,4,56,7$ correspond to satisfaction scores of $7,6,5,4,3,2,1$ respectively, for items $50,52,53,54,55$, and 56. Items $48,49,51,57,58,59$ are scored in reverse order so that higher scores indicate higher satisfaction. Mean scores can range from 1-7. This scale has been shown to be reliable and valid (Bowden, 1977; Frazier, 1976; Roach et al., 1971). Frazier (1976) found the test-retest reliability coefficient at 3 weeks to be .76 , Cronbach's alpha to be .97 , and all items to be significant at or beyond the .01 level of significance. The MAT (Locke \& Wallace, 1959) was administered as a criterion variable with validity coefficient of .79. Satisfied and dissatisfied couples, identified by peer ratings and professional marriage counselors, were tested by Bowden (1977) and found to significantly differ on the longer scale. Celebucki (1990) found a Cronbach's Alpha of .93 for the reduced scale and favorable correlation with a global measure of satisfaction $(r=.79)$ and the "Spanier" $(r=$ $.79)$. 
The third measure of satisfaction is a single item assessment of overall relationship satisfaction "global sat". Respondents used a 7 point Likert- type scale which ranged from 1 (extremely dissatisfied) to 7 (extremely satisfied), with the middle value of 4 denoting neutrality, (not satisfied but not dissatisfied). Single-item global measures have been used extensively in the study of relationship satisfaction (Grey-Little \& Burks, 1983). The global relationship satisfaction measure "global sat" is item 19 in Appendix A.

Perceived Partner Support for Educational Goals. Three measures of perceived support were obtained. Confidence in measures of perceived support as predictive of actual support is provided by Vinokur, Schul and Caplan (1987). The first measure of perceived "partner support" for educational goals, a 4 item scale used by the author at Time 1 and Time 2, is presented in Appendix A (item 44 to item 47). This scale was constructed by the author with items taken from the literature and conversations with re-entry women. Both positive and negative attitudes and behaviors are represented. Coefficient alpha in the initial study was found to be .84 (Celebucki, 1990). The second partner educational support measure is a subscale of "partner support" that assessed perceived "partner positive" response and is comprised of an attitudinal measure, "positive attitude towards school" (item 45); and a positive outcome, "being with partner makes it easier for me to attend school" (item 44). The third measure of partner educational support, also a subscale of "partner support" assessed perception of "partner negative" 
response to school and is comprised of a negative attitude, "amount that partner sees education as a threat," (item 46) and a negative outcome, "school as source of arguments and disagreements" (item 47). Respondents used a 7 point scale to indicate extent of agreement with each item. Items 46 and 47 were scored so that higher numbers indicated higher perception of support (lower negative perceptions). Mean values for all educational support measures can range from 1 to 7 .

Relative Income. Two items assessed income at Time 1 and again at Time 2: "Self income" is the participant's income (item 3 in Appendix A) and; "Partner Income" is partner's income (item 22 in Appendix A). From these items, additional measures of income were computed: "Change in self income" is Time 2 self income minus Time 1 self income; "Change in partner income" is Time 2 partner income minus Time 1 partner income and "Difference in income" is the result obtained when the participant's income score is subtracted from the partner's income score. A negative result would indicate participant had more income. Difference in income was calculated for both Time 1 and Time 2 separately to control for the effects of income differences within that time period. "Relative income" was computed by subtracting "change in self income" from "change in partner income". A negative result would mean the participant's income had increased relative to her partner's income, while a positive result would indicate that partner's income had increased relative to the participant's income. "Relative income" was used as the covariate with change variables in this study to 
control for the effects of changes in income between self and partner across the 2 time periods. Negative correlations among the "Difference in income" or "Relative income" measures and any of the decision-making, satisfaction, partner support or education measures are indicative of a positive relationship among increases in participant's income relative to her partner and increases in these measures.

Social Readjustment Measure. At Time 2, a checklist of recent life events based on the work of Holmes and Rahe (1967), Saranson (1978), Quina-Holland and Kanarian (1983) and modified by this author to include more events that are representative of women's life experience was used to assess "Stress". The scale is comprised of 51 items with space for 3 items to be written in by participant. It is presented in Appendix A, item 115 to item 169. Participants were instructed to check the item only if the event had occurred in the past 3.5 years. Items are scored as 1 if checked, and zero if not checked, and are summed to obtain a total score. Scores can vary from 0 to 54 . Items 135,140 , and 141 "outstanding personal achievement," "the ending of formal education" and "beginning new academic or training program," respectively, were excluded when assessing differences in stress levels among respondents at different education levels, as those women who had graduated or ended their education prior to graduation would be different from those who were still pursuing their education. Unweighted scores have been shown to be as good a predictor as weighted 
scores in the prediction of illness and depression (Kale \& Stenmark, 1983; Tausig, 1982).

Barriers to Education. A check list of 16 Barriers to Education with space for write-in items was provided. This is Item 112 in Appendix A. Items were selected from the literature on reentry students and from conversations with women students attending college.

Reliability of measures. All variables acting as covariates must be reliable. Prior research on scale development and present data collection procedures give no cause to expect unreliability of the measures. However, as a safeguard, reliabilities for the multi-item scales were assessed using SPSSX Reliability. Using the matched sample of Time 1 and Time 2 respondents, all scales used were found to be reliable at Time 1 (Celebucki, 1990) and again at Time 2. Coefficient alpha values ranged from .47 to .95 at Time 1 and from .37 to .95 at Time 2 . Decision-making scales in this study were less reliable than were satisfaction scales. At Time 1 the decision-making scales ranged in reliability from .48 to .85 , and at Time 2 from .37 to .78 . At both Time 1 and Time 2 , relationship satisfaction scales ranged in reliability from .94 to .95 . Reliability of the change in predicted decision-making scale was quite low (coefficient alpha $=.15$ ), but was greater (coefficient alpha $=.28$ ) when using scores from those respondents who were reporting on the same relationship at both time periods. 


\section{Results}

Qverview of Analyses

Pearson Correlations, partial correlations, regression analyses, Analyses of Variance (ANOVA) and Multivariate Analyses of Variance (MANOVA) were used to test the hypotheses and answer additional questions about the data. All correlations between Time 1 and Time 2 measures were based on scores from respondents who had been tested at both time periods and who, therefore, constituted a matched sample. In order to reduce the number of variables used in the regression analyses to an acceptable case to variable ratio, each individual's change score on all measures was computed by subtracting scores at Time 1 from scores at Time 2. Table 1 presents the means and standard deviations of these change scores.

Insert Table 1 about here

Demographics and Comparisons between Time 1 and Time 2

Statistically significant differences were found between those who, in 1988, agreed to be contacted at a later time and those who did not, with those agreeable to continued participation being more likely to be in current relationships and more satisfied with their relationships. Table 2 presents demographic information on the 78 women tested at both Time 1 and Time 2 who constitute the respondents in this study.

Of the 77 women who reported on income at Time 1:36\% $(\mathrm{n}=$ 28) were in category $7(\$ 15001-\$ 25000)$; $15 \%(n=12)$ were in 
category 1 (under $\$ 500) ; 13 \%(n=10)$ were in category 8 $(\$ 25001-\$ 35000) ; 10 \%(\mathrm{n}=8)$ were in category $6(\$ 10001$ $\$ 15000) ; 9 \%(n=7)$ were in category $5(\$ 6001-\$ 10000) ; 8 \%(n$ $=6)$ were in category $4(\$ 3001-\$ 6000)$; and $5 \%(n=4)$ were in category 2 (\$501-\$1500). The median income was category 7 , and $13 \%$ earned more than $\$ 35000$. Of the 78 women reporting on income at Time $2: 27 \%(\mathrm{n}=21)$ were in category $7 ; 13 \%(\mathrm{n}=$ 10) were in category $1,13 \%(n=10)$ were in category $8 ; 10 \%(n=$ 8) were in category $5 ; 10 \%(n=8)$ were in category $9(\$ 35001$ $\$ 50000) ; 8 \%(\mathrm{n}=6)$ were in category $4 ; 6 \%(\mathrm{n}=5)$ were in category 2 and $6 \%(\mathrm{n}=5)$ were in category 3 . The median income category at Time 2 was also category 7 , but $23 \%$ reported income over $\$ 35000$ at Time 2. Percentages in category 6 and 7 decreased, from Time 1 to Time 2, while percentages in category $8(\$ 25001$ - \$35000) remained the same and percentages in category 9 increased by $9 \%$. Twenty-four percent of the respondents who reported on income at each time period experienced decreases in their income category, $37 \%$ reported no change and $39 \%$ reported increases with $66 \%$ of those reporting increases, increasing one category.

Insert Table 2 about here

Within this matched sample, 97\% of the respondents reported on a current relationship at Time 1 , and $95 \%$ reported on a current relationship at Time 2. Presented in Table 3 are the means and standard deviations of the decision-making 
measures, the relationship satisfaction measures, and the perceived educational support measures.

\section{Insert Table 3 about here}

\section{Hypothesis 1}

Table 4 presents the Pearson correlations among all the change in decision-making measures, all the change in education measures, all the change in relationship satisfaction measures, all the change in partner support variables and all the change in income measures in order to examine the relationships among variables without controlling for income.

\section{Insert Table 4 about here}

In order to test hypothesis 1 , that with change in relative income of self and partner held constant, changes in decisionmaking will be correlated with changes in education, two sets of analyses were undertaken. The first was a set of partial correlations which controlled for differences in relative income by partialling "relative income" from correlations among decision-making variables and percent of educational progress; the second set of analyses was a series of ANOVAs with change in decision-making as the dependent variable, and "educational status" as the independent variable. Results of the partial correlation analyses can be examined in Table 5. All correlations between the percentage of educational progress and 
the change in decision-making scores reached significance when relative income was controlled.

Insert Table 5 about here

Partial correlations controlling for relative income were also undertaken with each of the individual scale items of the "predicted say" scale. Significant correlations were found between "percent of educational progress" and "change in more say in affection," "change in recreation," and "change in time spent together" $[(\mathrm{r}=.5201, \mathrm{p}=<.001),(\mathrm{r}=.3476, \mathrm{p}<.01),(\mathrm{r}=$ $.2965, \mathrm{p}<.05)$ respectively].

Respondents were grouped by Educational Status: Women who had withdrawn without completing their degree, those who were currently attending college, those who had completed their Bachelors degree, and those who had gone on to graduate programs. A series of ANOVAs were conducted to determine whether or not thses groups differed on the "change in decisionmaking" measures (Table 6). It can be seen that only the "change in more say" was significantly different among the four educational status groups $[\mathrm{F}(3,74)=2.83, \mathrm{p}<.05]$.

Insert Table 6 about here

Means on"change in more say" for group 1 to group 4 were as follows: $-.1422,-.0309, .0925, .3450$. Multiple range tests using the Tukey procedure revealed significant mean differences 
between group 1 and group 4, i.e., between those women who had withdrawn from college and those who had attended graduate school.

\section{Hypothesis 2}

The hypothesis that with change in relative income of self and partner held constant, changes in relationship satisfaction will be correlated with changes in education, was tested in a manner similar to that used for the decision-making measures. Two sets of analyses were undertaken. The first, a set of partial correlations which controlled for differences in relative income by partialling "relative income" from correlations among relationship satisfaction measures and "percent of educational progress"; results of the partial correlation analyses are supportive of the hypothesis as can be seen in Table 5. The second was a series of ANOVAs with "change in relationship satisfaction" as the dependent variable, and "educational status" as the independent variable. None of the ANOVAs produced significant results (Table 7).

Insert Table 7 about here

Additionally, significant Pearson correlations were obtained between "percent of education attained" and relationship satisfaction when conducted using data from women reporting on the same relationship at Time 2 as they reported on at Time 1: "change in global satisfaction," $(\mathrm{r}=.4628, \mathrm{p}<.01)$; "change in 
Spanier" ( $\mathrm{r}=.3276, \mathrm{p}<.01)$; "change in Roach," $(\mathrm{r}=.3445, \mathrm{p}<$ $.01)$.

\section{Hypothesis 3}

The hypothesis that change in decision-making is related to change in relationship satisfaction was tested by conducting Pearson and partial correlations. Examination of Table 4 reveals "change in more say" to be correlated with "change in Roach" ( $\mathrm{r}=$ $.2256, \mathrm{p}<.05$ ). With "relative income" as the covariate, partial correlations among change in decision-making and change in satisfaction (shown in Table 8), indicate that "change in more say" is correlated with "change in global satisfaction," $(r=.1937$, $\mathrm{p}<.05)$ and with "change in Roach" $(\mathrm{r}=.2795, \mathrm{p}<.05)$.

\section{Insert Table 8 about here}

Because the reliability of the "predicted decision-making" scale was low, (coefficient alpha $=.15$ ), so individual decision-making items were analyzed separately. Results of the Pearson correlations are found in Table 9. "Change in more say in affection" is related to changes in all three satisfaction measures: "change in global satisfaction" $(r=.3329, p<.01)$; "change in Spanier" ( $\mathrm{r}=.3542, \mathrm{p}<.01)$; and "change in Roach" $(\mathrm{r}=.2903, \mathrm{p}<$ .05). "Change in more say" in determining the amount of time spent together" is correlated with "change in global satisfaction" $(\mathrm{r}=.2406, \mathrm{p}<.05)$. "Change in more say in finances," however, is inversely related to "changes in global satisfaction" $(r=-.2666$, $\mathrm{p}<.05)$, contrary to prediction. 
Insert Table 9 about here

\section{Hypothesis 4}

As can be seen in Table 10, Pearson correlations show more significant correlations between Decision-making at Time 1 and Satisfaction at Time 2, than between Satisfaction at Time 1 and Decision-making at Time 2.

Insert Table 10 about here

Changes in decision-making were correlated with changes in the relationship satisfaction measures (Table 4). Each of the Time 1 measures was also correlated with its corresponding measure at Time 2 (Table 10) with correlations of .48 to .67 for the decision-making measures, and .56 to .71 for the relationship satisfaction measures. Pearson correlations in the cross-lag panel design revealed none of the Time 1 relationship satisfaction measures to be significantly correlated with the Time 2 decision-making measures, but all of the decision-making measures at Time 1 were found to be significantly correlated with either the Roach or Spanier satisfaction measures at Time 2 . These correlations are also shown in Table 9. Decision-making at Time 1 is shown to be a predictor of subsequent relationship satisfaction, in support of the hypothesis. 
Hypothesis 5

To test hypothesis 5, that change in self income is positively correlated with change in decision-making, subsamples of respondents were first selected according to relative income changes between Time 1 and Time 2. All those whose own income had increased since Time 1 while their partners income had remained the same or gone down $(n=17)$ were classified as those in which their individual decision-making scores should increase from Time 1 to Time 2; all those respondents whose income had decreased from Time 1 to Time 2, while their partner's income had stayed the same or increased $(n=16)$ were classified as those in which their individual decision-making scores should decrease from Time 1 to Time 2. All those respondents whose partner's income had increased from Time 1 to Time 2 while their own income had remained the same or decreased, (relative income of partner to self had increased) $(n=10)$ were analyzed to test the hypothesis that changes in relative income would be related to decision-making scores, i.e., decision-making of participant would decrease from Time 1 to Time 2. Separate repeated measures analyses of variance using SPSSX MANOVA were conducted on the decision-making measures. Results with the first sample, were somewhat supportive of the hypothesis that if self income increases, decision-making power will increase in that there was a significant change between Time 1 and Time 2 on the "global more say" measure: Means at Time $1=4.06$; Time 2 Means $=4.8$; $[\mathrm{F}(1,16)=6.35, \mathrm{p}<.05]$. For "more say" Time 1 Means $=4.2$ and 
Time 2 Means $=4.1[F(1,16)=5.63, \mathrm{p}<.05]$. While the results for the "global more say" measure were as predicted, those for "more say" were contrary to prediction. Changes from Time 1 to Time 2 in "final say" were not significant, nor were changes in the "predicted say" scale. Table 11 presents the relevant data.

Another series of within subjects repeated measures analysis of variance, conducted in the same way with the second subsample, to test the hypothesis that if self income decreases, decision-making power will decrease yielded no significant results. None of the decision-making power scales was shown to differ significantly from Time 1 to Time 2 as a function of decreases in respondent's own income from Time 1 to Time 2. A third series of analyses, similarly conducted, to assess the impact of changes in relative income (increases in partner's income with no increase in participant's income) on the participant's decisionmaking, was supportive of the hypothesis and indicated a significant decrease from Time 1 to Time 2 on participant's scores on the "predicted say" scale: Means at Time $1=4.48$; Means at Time $2=4.1 ;[F(1,9)=10.06, p<.05]$.

Insert Table 11 about here

While increases in self income relative to that of partner were shown to be predictive of increases in "global more say," and increases in partner's income relative to that of the participant were shown to result in decreases in "predicted say," it is notable that increases in self income relative to that of partner were 
associated with decreases in the "more say" scale measure. This last finding is contrary to the hypothesis of a positive relationship between income and decision-making.

In as much as the reliability of the predicted decision-making scale was low (coefficient alpha $=.15$ ), Pearson correlations (see Table 9) were conducted, with the total sample of respondents $(\mathrm{N}=78$ ) among the change in income variables ("change in self income," "change in partner income" and "relative income") and the individual items comprising the "predicted say" scale. Significant correlations supportive of the hypothesis were obtained only with the "change in more say in finances" which was correlated with change in "relative income" $(r=-.2662, p<$ .05). As relative income changes in the direction of the participant (becomes more negative), more say in finances increases. When women were reporting on the same relationship, correlations were higher, i.e., "more say in finances" with "change in self income" $(r=.2387, \mathrm{p}<.05)$, and with "relative income" $(\mathrm{r}=-4223, \mathrm{p}<.01)$.

Additional analyses were conducted in an effort to understand the negative relationship between increased income and changes in "more say." The sample was split by "educational status" into four groups (withdrawn, continuing undergraduate, completed bachelors, and attended graduate school) and Pearson correlations between Time 2 income and Time 2 decision-making power were obtained within each group. Pearson correlations were also conducted within each group between the changes from Time 1 to Time 2 in income and decision-making. Results 
indicated that among those women who have withdrawn $(n=22)$, "self income" is positively correlated with the "global more say" measure $(\mathrm{r}=.4936, \mathrm{p}<.05)$ in support of the hypothesis. No Time 2 correlations among income and decision-making reached significance within the group of women who were continuing their undergraduate education $(n=27)$, but results indicated that a Time 1 to Time 2 change in income variable "relative income" was correlated with "change in more say" ( $\mathrm{r}=-.5027, \mathrm{p}<.01)$ and "change in self income" was correlated with "change in more say in finances" $(r=.3981, p<.05)$. Both of these findings are supportive of the hypothesis. Furthermore, changes in partner's income were negatively correlated with changes in participant's "more say" in the area of sex, affection and leisure time $[\mathrm{r}=$ $-.4098(\mathrm{p}<.05), \mathrm{r}=-.5345(\mathrm{p}<.01)$, and $\mathrm{r}=-.4026(\mathrm{p}<.05)$, respectively]. Among those women who had completed their undergraduate degrees $(n=17)$, "self income" was negatively correlated with "more say," $(\mathrm{r}=-.5288, \mathrm{p}<.05)$, and "partner income" was also negatively correlated with "more say" $(\mathrm{r}=$ $-.5784, p<.05$ ). At Time 2 , women with higher earnings of their own and women whose partners had higher earnings had lower amounts of "more say" than women with lower self or lower partner earnings.

Hypothesis 6

In a manner similar to that used with the decision-making measures, a series of Repeated Measures Analysis of Variance (Time 1, Time 2) using SPSSX MANOVA were conducted with each of the relationship satisfaction measures to test the 
hypothesis that partner's income is positively correlated with relationship satisfaction. No significant differences were found from Time 1 to Time 2 in any of the participants' satisfaction scores among those participants whose partners had higher incomes at Time 2 than at Time 1. Similar analyses conducted among those whose partners' incomes had decreased from Time 1 to Time $2(n=8)$, showed no significant change in satisfaction measures.

Pearson correlations using the entire sample $(\mathrm{N}=78)$ were conducted. Correlations among the change in partner income from Time 1 to Time 2 and the change in relationship satisfaction measures were non-significant, as were the correlations among Partner income at Time 2 and Time 2 satisfaction.

As a further test of hypothesis 6, that increases in partners' incomes are correlated with increases in satisfaction, Pearson correlations were conducted among the income and satisfaction measures using only those women who had not yet completed their undergraduate degree $(n=49)$. For these women, "relative income" (the difference between Time 1 and Time 2 differences between self income and partner income) was correlated with change in relationship satisfaction on the Roach measure $(r=$ $.3308, \mathrm{p}<.05)$ and on the Spanier measure $(\mathrm{r}=.4397, \mathrm{p}<.05)$. Among this group of women, the more that partner's change in income had increased relative to the participant's change in income (positive value), the more satisfied the participant was with the intimate relationship. Change in own income from Time 
1 to Time 2 was negatively correlated with the change in Spanier satisfaction measure $(\mathrm{r}=-.3205, \mathrm{p}<.01)$ within this group of women who have not yet completed their undergraduate degrees. The hypothesis that changes in partner income will be correlated with changes in participant's satisfaction was supported only when changes in self income were controlled, and only among those respondents who had not yet completed their undergraduate degrees. There was no support for the hypothesis across all respondents, or among those who had completed their undergraduate degrees.

Hypothesis 7

Pearson correlations showed that partner educational support at Time 2 "partner support" was significantly correlated with all of the satisfaction measures at Time 2: "global Satisfaction" ( $\mathrm{r}=$ 4770, p < .01); "Spanier" ( $\mathrm{r}=.5875, \mathrm{p}<.01)$; "Roach" $(\mathrm{r}=.6492, \mathrm{p}$ $<.01)$; as well as with one decision-making scale, "final say" ( $\mathrm{r}=$ $.3279, \mathrm{p}<.01)$. Changes in "partner support" from Time 1 to Time 2 were also correlated with changes in satisfaction from Time 1 to Time 2 (Table 4): Change in "Partner support" with Change in "Global Satisfaction" $(r=.3382, p<.01)$; with Change in "Spanier" $(\mathrm{r}=.3095, \mathrm{p}<.01)$; and with Change in "Roach" $(\mathrm{r}=$ $.3510, \mathrm{p}<.01)$.

Pearson correlations were conducted to determine whether respondents' responses to positively phrased partner educational support items or to negatively phrased educational support items (recoded so that higher scores are indicative of less negative perceptions) were more highly correlated with 
relationship satisfaction. Results of the Pearson Correlations (see Table 4) indicated that "partner negative" but not "partner positive" was significantly correlated with the Spanier, and the Roach relationship satisfaction measure and supportive of the hypothesis. As can be seen, both "partner positive" and "partner negative" were significantly correlated with the Global

Satisfaction measure.

Exploratory Analyses

Barriers to continuing education. The majority of respondents (61 of 84 , or $73 \%$ ) reported at least one barrier to education with $52(62 \%)$ reporting at least 2 barriers and $34(40 \%)$ noting at least 3 barriers. Respondents could check any or all items. Of the 168 responses checked, family responsibilities, lack of time, illness of self or a family member, employment and financial problems were the most frequently selected. These barriers were neither independent nor exhaustive. Several responses were in the category "other," with 31 respondents writing in at least one other barrier, 16 writing in two others, and 11 writing in 3 other barriers. Moving, needing to transfer to another University or to another campus within the University because of requirements for their major, and birth of children were most frequently added. An ordered listing of Barriers to education is provided in Table 12.

Insert Table 12 about here 
Significant correlations were obtained between relationship satisfaction measured at Time 2 and the barrier "not enough time": "global Satisfaction" $(r=-.2243, p=<.05)$; "Spanier" $(r=-$ $.2447, \mathrm{p}=<.05)$; "Roach" $(\mathrm{r}=-.3159, \mathrm{p}=<.01)$. The most frequently selected barrier "family responsibilities," was negatively correlated with several measures at Time 2: "partner support" for education, $(r=-.2562, \mathrm{p}=<.05)$; "partner positive support" $(\mathrm{r}=-.3414, \mathrm{p}=<.01)$; "final say" $(\mathrm{r}=-.2565, \mathrm{p}=<.05)$ and "education status" $(\mathrm{r}=-.2546, \mathrm{p}=<.05)$. Employment problems were negatively correlated with change in "partner positive" educational support $(\mathrm{r}=-.2715, \mathrm{p}=<.05)$. In addition to "family responsibilities', barriers that were negatively correlated with "educational status" included: illness, $(r=$. $.2443, \mathrm{p}=<.05)$; and financial problems $(\mathrm{r}=-.2375, \mathrm{p}=<.05)$.

Chi squares analyses indicated that a significantly higher percentage of women in the withdrawn group were likely to report a barrier to education (86\%) than in the continuing group (59\%). $\left.\mathrm{X}^{2}(1, \mathrm{~N}=49)=7.79, \mathrm{p}<.01\right)$. As can be seen from Table 13, which displays the top 5 barriers for women who have not yet completed their undergraduate degree, grouped according to whether or not they have withdrawn from or are continuing with their education, the pattern of barriers was essentially the same for these groups except for financial problems (more withdrawers checked this barrier), and illness (more continuers checked this barrier).

Separate Chi squares analyses conducted with each of the barriers revealed no significant differences between the types of 
barriers reported by women who had withdrawn and women who were continuing their undergraduate educations.

Insert Table 13 about here

Financial problems and family responsibilities were suggestive of group differences in that the obtained probability for each was $\mathrm{p}=.08$.

In order to determine whether or not the level of education at Time 1 (low or high) was predictive of perception of educational barriers at Time 2, Time 1 participants were split at the median number of credits earned to date into low and high groups. Chi squares produced no significant results.

Perception of partner educational support. The means of change in "Partner support" for education were suggestive of a curvilinear relationship, and when tested using SPSSX ANOVA with subcommand polynomial $=2$, significant results were obtained $[F(3,72)=5.24, \mathrm{p}<.05]$ for the weighted quadratic term. Means and standard deviations for the groups are as follows: group $1(\mathrm{n}=22) \mathrm{M}=-.1682$, sd 1.5 ; group $2(\mathrm{n}=27) \mathrm{M}=$ $.3284, \mathrm{sd}=.95 ;$ group $3(\mathrm{n}=17) \mathrm{M}=.6824, \mathrm{sd}=1.17$; and group 4 $(\mathrm{n}=10) \mathrm{M}=-.2200, \mathrm{sd}=.61$. Multiple range tests using the LSD procedure showed group 1 and group 3 to be significantly different. Changes in Perceived Partner educational support are significantly different among the group of students who have withdrawn (group 1), and the group who have graduated with the bachelor's degree (group 3). Women who have terminated 
their education with the Bachelor's degree perceive more change in their partner's educational support than women who have terminated their education prior to receiving the degree.

Income and Satisfaction. Additional analyses related to income were undertaken. The Time 2 sample was split by "educational status" to examine the cross-sectional within group correlations among income and satisfaction: Within group 1 (women who have withdrawn from school), "partner income" was correlated with "global satisfaction" $(\mathrm{r}=.5454, \mathrm{p}<.05)$. Within the group of women who have gone on to graduate school $(\mathrm{n}=10)$, Time 2 "self income" was positively related to Time 2 "global satisfaction" $(\mathrm{r}=.6506, \mathrm{p}<.05)$. In no other groups did correlations between Time 2 income and Time 2 relationship satisfaction reach significance.

Pearson correlations between Time 1 to Time 2 differences in income and Time 1 to Time 2 differences in relationship satisfaction were also conducted within each group. Within group 1 (those who have withdrawn), change in "relative income" was correlated with change in "global satisfaction" ( $r=$ $.7685, \mathrm{p}<.01)$, change in "Spanier" ( $\mathrm{r}=.6295, \mathrm{p}<.01)$, and change in "Roach" $(r=.6729, \mathrm{p}<.01)$, supportive of Hypothesis 6.

Income and Education. Time 1 "self income" is negatively correlated with "educational status" at Time $2(\mathrm{r}=-.3390, \mathrm{p}<$ .01). At Time 2, "partner income" is positively correlated with number of graduate courses taken at Time $2(\mathrm{r}=.3192, \mathrm{p}<.01)$.

Income and Perception of Partner's educational support. Changes in "partner income" were positively correlated with 
changes in perceived "partner support" for education. Using the entire matched sample $(\mathrm{N}=78)$, Pearson correlations among the change measures show change in partner's income to be significantly correlated with change in participant's perception of partner's educational support $(r=.2838, \mathrm{p}<.05)$. The difference in income at Time 1 (partner income-participant income) was inversely related to perceived partner educational support at Time 2, $(\mathrm{r}=-.3265, \mathrm{p}<.05)$ with higher self income relative to partner income at Time 1 predictive of higher perceived educational support at Time 2. Time 1 partner income is inversely related to perceived partner educational support at Time $2(\mathrm{r}=-.4012, \mathrm{p}<.01)$.

Among women who have not yet completed their undergraduate degree, (withdrawers and continuers) changes in income were related to changes in perceived educational support. "Relative income" is associated with change in perception of "positive support" $(r=.3258, p<.01)$. Time 1 to Time 2 change in "partner income" was positively correlated with changes from Time 1 to Time 2 in perceived "partner positive" and "partner negative" support $(r=.3037, \mathrm{p}<.05)$ and $(r=.3124, p<.05)$, respectively. "Partner negative" attitude and behavior have been scored so that positive increases signify more support. 
Summary of major findings

The main research question asked of this longitudinal study of re-entry women was whether or not changes in their educational status could predict changes in decision-making and in satisfaction within ongoing, long-term heterosexual intimate relationships if change in income is accounted for. The answer is yes. Within an ongoing relationship, the decision-making of women can be altered by changes in their education. Increases in "global more say," "more say," "final say," and "predicted say," were found to be associated with increased education, with the change in the "predicted say" yielding the highest correlation.

Correlations between change in education and change in the global measure of satisfaction reached significance, as did correlations between changes in education and changes in all the relationship satisfaction measures when women were reporting on the same relationship at Time 2 as they reported on at Time 1. With the effects of income controlled, changes in education were found to be significantly related to changes in relationship satisfaction on all the satisfaction measures.

Another major research question was the extent to which changes in relationship satisfaction and changes in decisionmaking are positively related. Changes in "more say" in finances, affection, and time spent together were significantly correlated with changes in relationship satisfaction, however, change in finances was contrary to the hypothesis in that increases in "more say" in finances from Time 1 to Time 2 was associated with decreases in relationship satisfaction from Time 1 to Time 
2. Results indicated that women's changes in decision-making from Time 1 to Time 2 were associated with changes in relationship satisfaction from Time 1 to Time 2 when changes in income were controlled. When relative income was held constant, change in decision-making "more say" and change in relationship satisfaction "global satisfaction" and "Roach" were positively related.

The effect of income as a structural variable on both decisionmaking and relationship satisfaction is relevant to this research question. When looking at the relationship between changes in income and changes in decision-making power, increases in income, both own and partner's, and changes in relative income are more important than decreases in income. Furthermore, contrary to prediction, increases in income are related to decreases in "more say" decision-making in the group of women who have terminated their education with the bachelors degree. For all respondents, changes in income were most predictive of changes in decision-making in finances.

The relationship between income and relationship satisfaction is not straight-forward. Increased self income is positively related to increased relationship satisfaction only for those women who have gone on to graduate school. For undergraduate women, the relationship is reversed: the more self income, the less satisfaction. For women who have completed their undergraduate degree, no relationship between income and relationship satisfaction was found. Increases in partner's income relative to increases in self income from Time 1 to Time 
2 were predictive of increases in relationship satisfaction for undergraduate women.

A third research question was whether decision-making is predictive of satisfaction, or vice versa. The evidence supports the conclusion that for this group of respondents, women who have gone back to school and who are in long-term intimate relationships, decision-making at Time 1 is more predictive of relationship satisfaction at Time 2 than relationship satisfaction at Time 1 is predictive of decision-making at Time 2.

The final research question asked how partner's support (both the perception of partner's support for the woman's education and partner's income as tangible support) impacts relationship satisfaction. It was hypothesized that the relationship between these variables would be positive. Change in partner's income was found to be positively correlated with changes in perceived partner support which was positively correlated with changes in relationship satisfaction. It was the change in relative income, however, rather than the change in partner's absolute income that was predictive of change in relationship satisfaction.

Change in relative income and in partner's absolute income were both positively related to satisfaction only for women who had not yet completed their undergraduate degrees. For all respondents, as predicted, change in perception of partner's support for education was significantly and positively correlated with all measures of change in relationship satisfaction. These variables, found to be correlated in the previous study 
(Celebucki, 1990) were also found to be positively correlated when measured at Time 2 .

Those women who had withdrawn from college were significantly different from those who were still enrolled in undergraduate programs, with the former reporting more barriers to their continued education: $86 \%$ of those who had withdrawn from college checked at least one barrier compared to $59 \%$ of those who were continuing in school. 


\section{Discussion}

Change in education is correlated with change in decisionmaking as measured by the "predicted say" scale when the effects of changes in relative income are controlled. This scale deals with variables most likely to be affected by increased education, i.e., decision-making regarding matters of finances, recreation, affection, friends, time spent together, leisure time activities, and career and employment decisions. At Time 2, as predicted, there were differences in the amount of change in the global more say measure between those women who had withdrawn from school and those who had gone on to graduate school. Time 1 to Time 2 change in education, best represented by the percentage of credits needed to graduate that were earned over the past 3.5 years, was significantly correlated with Time 1 to Time 2 change in every decision-making scale. This relationship was even stronger when change in relative income was controlled. Whereas we know that education is correlated with power in cross-sectional studies of heterosexual ongoing relationships (eg., Howard, Blumstein \& Schwartz, 1986), the sample of women in this study altered their decision-making power over the past three and one half years, and those with the greatest increases in education had the greatest increases in their decision-making.

Income changes from Time 1 to Time 2 in both self income and participant's relative income were shown to be most positively correlated with changes in decision-making in the 
area of finances. Increases in partner's relative income were negatively correlated with participant's decision-making on the "predicted say" measure. Increases in partner's income from Time 1 to Time 2 resulted in decreases in participant's "say" in the areas of affection and leisure time. While increases in "self income" were related to positive "changes in more say in finances," increases in own income relative to those of partner's income resulted in increases in the "global more say" and in decreases in decision-making on the "more say" scale from Time 1 to Time 2 .

Among the women who have graduated, but did not go on to graduate school, "more say" decreased as their relative incomes went up suggesting a restructuring or abdication of certain responsibilities or possible effects of outside influences (e.g., dictates of job, scheduling, older children, etc.). Pleck (1979) found that employed women as compared to full-time homemakers did slightly less family work, and Maples (1985) reporting on dual career couples indicated that many of the woman's previous responsibilities in the family get hired out, delegated, or remain undone. In as much as "more say in finances" increases even as "more say" decreases, it is possible that certain responsibilities are paid for out of the woman's increased income.

Changes in education were predictive of changes in relationship satisfaction when changes in relative income were controlled or when women were reporting on the same relationship at both time periods. While most Time 1 couples 
were still intact at Time 2 , it is notable that for those in the same relationship, there were more significant correlations among the education and relationship satisfaction measures. One implication of this finding is that relationships may be terminated for those who have increased education without increased satisfaction. Another is that women with satisfying relationships can more successfully continue with their educational pursuits. Education may also increase the level of satisfaction within ongoing relationships. Hooper (1979) and Pleck (1973) report increased satisfaction for both husbands and wives among couples where the women has re-entered college or the workforce. In as much as Grey-Little and Burks (1983) found decision-making power to be related to relationship satisfaction, it is possible that decision-making is a mediating variable between change in education and change in relationship satisfaction.

Changes from Time 1 to Time 2 in decision-making regarding general "more say", the "more say" scale, and in changes in "more say" in areas of affection, recreation, and amount of time spent together were related to changes in relationship satisfaction. While correlations are modest, ranging from .26 to .34 , they are above those results obtained in cross-sectional national surveys (Campbell, 1980), and are further increased when changes in relative income are controlled. It is possible that certain items in the "more say" scale are not as important to women at Time 2 as they were at Time 1 , and therefore do not have the same 
impact on relationship satisfaction at Time 2 as they had at Time 1.

All measures of decision-making at Time 1 were positively correlated with measures of relationship satisfaction at Time 2 , whereas none of the measures of relationship satisfaction at Time 1 was significantly correlated with measures of decisionmaking at Time 2. Correlations between Time 1 and Time 2 scores were significant when each of the measures of decisionmaking and relationship satisfaction was correlated with itself. This suggests that decision-making is antecedent to relationship satisfaction, and extends the cross-sectional research by Whisman and Jacobson (1989) in which inequity and dissatisfaction with task distribution in marriages was significantly correlated with depressive symptoms.

Income as well as education can impact decision-making and relationship satisfaction. Partner's income can be seen not only as a factor in decision-making but also as a tangible support for re-entry women. An examination of the relationship between changes in own income and changes in satisfaction among withdrawers and continuers indicates that the more one's own income declines from Time 1 to Time 2, the more satisfied the participant becomes with her intimate relationship. In as much as change in partner income was unrelated to changes in relationship satisfaction, it appears that it is the relative increase rather than the absolute increase in partner's income that is predictive of increases in participant's relationship satisfaction. A re-entry student who is able to earn less money at Time 2 
than at Time 1 may see this as evidence of partner's financial support, which could translate into increases in relationship satisfaction especially for undergraduate women. In the same way, partner's decrease in income from Time 1 to Time 2 relative to participant, may indicate that she has reduced support from her partner and therefore becomes less satisfied. In the present study, higher partner to self income ratio was positively related to both higher satisfaction and to changes in education. Change in partner income from Time 1 to Time 2 was found to be positively related to change in perceived partner support for education, and relative income changes in the direction of increased partner to participant income (positive) were correlated with increases in perception of partner's educational support (positive). In as much as the majority of the women surveyed had not yet completed an undergraduate degree $(n=49)$, lack of own income, and by implication, availability of partner's income could be viewed by many reentry women as an element of support as well as a necessity. This concurs with findings reported by Ostrow, Paul, Dark and Behrman (1986) that re-entry women as compared to re-entry men college students report more reliance on their partners' incomes.

Higher partner income may allow for less income production by the participant, thus increasing the rate at which she undertakes education. Partner's lower income at Time 1 may result in financial problems necessitating the discontinuing or the slowing down of educational pursuits, as the re-entry 
student's income may be needed for family survival. This conclusion (similar to that of Meers \& Gilkison, 1985) is supported by the observation that women who withdrew from school were twice as likely as women who were continuing in their undergraduate education to select financial problems as a barrier to their education.

Gerson (1985) found famiy income to be negatively related to self reported role strain (not enough time). In the present study, respondent's perception of employment problems as barriers to education was associated with lower perception of partner support for their education. This further supports the conclusion that for intact couples, partner income is a tangible support as well as a factor in decision-making. Predictions based on viewing income as a power variable only without consideration of its support function may be too simplistic. This may be especially relevant for understanding the obtained relationships among income and satisfaction measures for women who had not yet completed their undergraduate degree. Furthermore, in heterosexual couples, a change in a male partner's income may be positively related to a change in his satisfaction, and this, in turn, may affect the women's level of satisfaction.

It is also possible that women with less differences in income between themselves and their partners at Time 1 were also more egalitarian at Time 1, than those of women whose differences in income between themselves and their partners were greater; and that because of this egalitarian relationship, perception of partner's educational support increased with the 
increased demands of ongoing education. These relationships may have been more egalitarian even prior to the woman's reentry to education as Hooper (1979) implies in her research on couples where the woman has returned to school.

The partner who earns less money at Time 1 , as compared to one who earns more, may also see the practical benefit to the family of his wife's attaining an education in terms of long-term enhanced family income and may therefore be more supportive of her earning a bachelor's degree. Perception of support was shown to be highest among those women who completed their bachelors' degrees. Yet, higher partner income was positively related to the number of graduate courses taken. It would seem that lower self income and higher partner income favor higher educational attainment for women, but higher self income and lower partner income at Time 1 and change in partner income result in higher perception of partner support for education.

Self income as a power variable was expected to be positively related to relationship satisfaction, but findings were contrary to prediction among those participants (both withdrawn and continuing) who had not yet completed an undergraduate degree. Only among women who had gone on to graduate school were changes in self income positively related to changes in relationship satisfaction. Rhode Island, and much of the Northeast, have undergone economic recession during this longitudinal study. These data revealed that partner's income has declined overall, while participant's income has increased, with relative income moving in the direction of less difference 
between the two at Time 2 than at Time 1. This may mean that women are leaving school to work; reducing time at school to increase time in the workplace; increasing time in the workplace while maintaining their commitment to their education; or graduated and working at higher salaries. In any of the aforementioned cases, a male partner may be threatened both by his decreased income and by his partner's increased income, and this, in turn, may alter the participant's level of satisfaction with the relationship.

Huston and Vangelisti (1991) reported that wives of husbands who exhibited negativity became more negative over time. Partner's negative attitude towards the re-entry woman's education may affect satisfaction much the same way as husbands negative attitude towards wives' employment has been found to negatively affect the wives' overall satisfaction (Hirsch and Rapkin, 1986). Women in the present study who perceived their partners as arguing over, or threatened by their education were less satisfied with their relationships than women for whom this was not the case. Furthermore, Time 1 to Time 2 change in negative perceptions of partner support was significantly correlated with the Time 1 to Time 2 change in the Roach and the Spanier relationship satisfaction measure whereas the Time 1 to Time 2 change in perception of positive partner support was not.

The educational barrier of not enough time (the number 2 barrier reported by all respondents), used in the literature as evidence of role strain, was negatively correlated with 
relationship satisfaction at both Time 1 and Time 2. Anecdotal evidence from women at the College of Continuing Education (CCE) at the University of Rhode Island, and comments on the research questionnaire used in this study, suggest that when they first began attending school, their families and partners reported no negative impact. Women worked their school and study schedules around their family responsibilities: "The books came out at 9 am and were put away before 5 p.m." Only as school progressed, and the demands increased (perhaps as two courses per semester were taken or as students became more in need of their partner's accommodation and support), did partners feel the impact of the new situation. It is probable that women attending graduate school have increased demands on their time and energy, may be approaching or surpassing the education level of their partners, and may be reducing their financial contribution, and increasing, at least in the short term, their financial liability. All could impact on their perception of partner's support for their educational goals.

It is also possible that as a woman earns more income, her economic dependence is reduced, and she may experience more dissatisfaction with her prior level of decision-making power within the relationship. This may be especially true if she perceives her partner as offering nothing in place of his previously higher relative income as tangible support while she has increased her financial contribution. Research by Nye (1974) who found "career" wives to be more satisfied than the "at home" wives or "working" wives, but who also found all 
employed wives to have more decision-making power than "at home" wives may be helpful in understanding these results. The income level of most women surveyed in this study is more suggestive of "working" than "career" wives. Perhaps as reentry students' incomes reach "career" levels, decision-making and satisfaction will be more highly correlated.

We know that many changes occur in the lives of students in a College of Continuing Education as they further their education. Students typically stop and restart several times in their reentry careers, as the demands of family and employment change (Gerson, 1985; Hildreth et al, 1983; Holiday, 1985; Meers \& Gilkison, 1985). While no hypotheses tested in this study were directly concerned with barriers, it is instructive to note the kinds of barriers that re-entry women see as problems as they undertake their education.

Most of the women in this study (73\%) identified at least one barrier as relevant to them and the majority of women (52\%) reported two barriers. At Time 2, women who had been above the median of credits earned toward their undergraduate degree at Time 1 were comparable in both the numbers and pattern of barriers reported at Time 2 to those women who were below the median in credits earned towards their undergraduate career at Time 1. But while women's educational attainment at Time 1 did not predict the barriers experienced in the subsequent 3.5 years, three of the barriers experienced in the 3.5 year period did correlate with educational status attained by Time 2 (family responsibilities, illness, and financial problems). 
Among all re-entry women, the barrier identified with the second greatest frequency (not enough time) was inversely related to measures of satisfaction at both Time 1 and Time 2 . Another frequently identified barrier (employment) was inversely related to perceptions of partner educational support, suggesting that not working and depending on partner's income may be indicative of increased partner support. Zick and McCullough (1991) reported significantly higher increases in wives, as compared to husbands, total time spent in employment, in education and on family work, and Gilbert (1991) found that while younger men assumed that their future wives will work, men don't see this as having any impact on their family and work roles. Having "not enough time" may be the result of a less satisfying intimate relationship that doesn't allow for the negotiation of changing roles and duties as the reentry woman continues her education. Whisman and Jacobson (1989) and Aida and Falbo (1991) found degree of task sharing and equality in income provision to be related to increased relationship satisfaction among wives. Interestingly, "not enough time" did not discriminate between women who were continuing their education and those who had withdrawn from college.

\section{Cautions and concerns}

Over 10 percent of those who agreed to ongoing participation in this study were not reachable because of lack of correct mailing address, therefore, it is possible that intact couples may be overrepresented. Those who responded at Time 2 may also 
have been more likely to be in relationships and to be more satisfied with those relationships than those who could not be located or who chose not to respond. This is not necessarily a problem, since the intent of this investigation was to examine longitudinal changes in satisfaction and decision-making power within ongoing relationships as a function of changes in level of education. However, in terms of an accurate assessment of the difficulties encountered by re-entry women, or changes that occur as they alter the status quo of a long term intimate relationship, this study may be underreporting the cases where the relationship is no longer intact or has become less satisfying. It is also possible that women who have transferred to another college or who are currently attending graduate school would be within this unreachable group.

Respondents with any amount of data missing from their questionnaires at Time 2 were significantly more likely to be less satisfied with their relationships and to have lower perceptions of partner's support for their education than those who provided complete data. There were no differences in decision-making among those with complete and incomplete data. Women may be reluctant to state that they are not satisfied or feel unsupported by their partners, and may chose to skip items that reveal this dissatisfaction.

Smaller numbers in the group of women who have gone on to graduate school reduces the powers of ANOVA, and small numbers combined with small effect sizes precludes the use of MANOVA with all dependent measures included. A final issue 
involves the use of relative income as a covariate. While the partialling out of relative income in order to control for differences in income is an appropriate statistical procedure, income and its effects cannot easily be separated in real life intimate relationships. Money and the control over money exert a powerful influence on decision-making and satisfaction within intimate relationships.

Directions for Further Research

It may well be that power within a relationship, here operationalized as decision-making, must be present at a minimal level for an adult woman to begin school at all. A study that examines changes in decision-making and relationship satisfaction in women who have enrolled in undergraduate programs, compared with women who have not undertaken further education but are similar on demographic variables, should be helpful in determining if this is the case. Furthermore, although within-couples research has shown a positive correlation between educational level and power (Blumstein \& Schwartz, 1983; Caldwell \& Peplau, 1984), changes in education may contribute minimally to changes in the power balance in a cohabiting, long-term relationship as measured here.

Anecdotal reports from the students in the current sample suggest that women keep a low profile about their school achievements so as not to threaten their partners. This is a far different situation from that in laboratory experiments where manipulation in the amount of feedback concerning expertise and competence given to both members of the dyad was found 
to alter the leadership position of women in mixed dyads (Fleischer \& Chertkoff, 1986; Nyquist \& Spence, 1986). The actual attainment of a degree may be a recognition of competence, while the individual coursework leading to the degree is not. A measure of the re-entry student's comfort in informing her partner of school related activities and achievements may be helpful in determining how ongoing education changes decision-making.

It was expected when this study was undertaken that a longitudinal investigation would permit the examination of change related to the termination of both education and relationships, but only the termination of education could be assessed since nearly all of the women respondents were within the same relationship at Time 2 as they had been in at Time 1 . Further investigation of re-entry students who have terminated relationships is warranted.

Although participant's income level relative to her partner's was considered in this study, participant's education level relative to her partner's was not considered. It may be that partner's educational support is related to his own education level. A change in relative education, similar to a change in relative income, may also have an impact on decision-making within the couple. Fowers (1991) found within couples differences in egalitarianism to be related to within couple differences in education, with less difference in education correlated to more support for egalitarianism in decisionmaking. Grey-Little and Burks (1983) found that satisfaction is 
highest in relationships where both partners have equal power, but they noted that equality can mean within separate spheres as well as equality in all aspects of the relationship. Increases in overall more say and more say in finances, recreation, time spent together, leisure activities, career, friends, and final say in employment were predicted to increase with increases in education, and partial support for these predictions was obtained. Further investigation of changes in equal say within the same areas of decision-making should yield interesting findings.

Collecting information from re-entry women's partners on decision-making, and satisfaction may help to understand the conditions under which changes in decision-making are positively related to changes in satisfaction. It is also probable that items on the decision-making scale are not equally important to re-entry women, and that the importance of items may change during the course of their education. Reliability of the decision-making measures was lower at Time 2 than at Time 1 , but reliability of the satisfaction measures was the same. A larger sample of women at both time periods would allow for factor analysis of the measures, which would be helpful in examining these changes. 
Appendix A 
1. Year of birth?

2. What is your total number of accumulated college credits (at URI and elsewhere) ? (If you are not sure, make your best guess)

3. What is the amount of annual income that you personally receive from all sources? Do not include another's income in this amount. Please circle the appropriate number.
1. under $\$ 500$
5. $\$ 6001-10000$
9. $\$ 35001-50000$
2. $\$ 501-1500$
6. $\$ 10001-15000$
10. $\$ 50001-65000$
3. $\$ 1501-3000$
7. $\$ 15001-25000$
11. over $\$ 65000$
4. $\$ 3001-6000$
8. $\$ 25001-35000$

4. Which best describes your present employment situation? Circle ALL that apply.

1. Taking care of the household is my full time job.

2. Employed full time

3. Employed part-time

4. Retired

5. Employed but temporarily not working due to illness, strike, etc.

6. Full-time student

7. Part-time student

5. What is your present occupation, if working at a paid job?

6. How far do you plan to go in college? Circle one answer.

1. I do not plan to continue in school.

2. I will continue taking courses but have no plans for a degree.

3. Bachelor's

4. Master's

5. Doctorate

6. Other (please specify)

7. Have you ever been involved in an intimate sexual relationship?

Circle one answer. Yes No

If you answered no, please go to top of page 11 , \#105

If you answered yes, please continue

For the next 8 items, please circle correct response.

8. How many times have you been legally married? $\begin{array}{lllllll}0 & 1 & 2 & 3 & 4 & 5+\end{array}$

9. How many times have you lived in an intimate sexual relationship including marriage? $\quad 0 \quad 1 \quad 2 \quad 3445$ or more

10. Are you: a. involved in an intimate sexual relationship? Yes No

b. currently living with this person? Yes No NA

If you answered Yes to quest 10 , part a, please answer the rest of this survey in terms of this relationship.

If you answered No to 10 , but have lived previously in an 
intimate sexual relationship, please choose the relation-ship that was the longest lasting and answer the rest of this survey based entirely on that relationship.

If you answered No to question 10 and never lived with an intimate sexual partner, please go to top of page 11 , \#105.

11. Do (did) you consider yourselves a couple? Yes No

12. Were you involved in this relationship in January of 1989 ? Yes No

13. In general who has (had) more say about important decisions affecting your relationship? Circle any one of the numbers on the following scale (1-7) that best reflects your answer.

\begin{tabular}{lll}
$\begin{array}{l}\text { I } \\
\text { much } \\
\text { more }\end{array}$ & $\begin{array}{c}\text { Partner and } \\
\text { I about } \\
\text { equally }\end{array}$ & $\begin{array}{l}\text { Partner } \\
\text { m uch } \\
\text { more }\end{array}$ \\
\hline
\end{tabular}

14. Sex of partner? Female Male

15. How old is your partner (present age)? ___ years.

16. Occupation of partner?

17. How long have (had) you been living together? __yr__mo NA (If a past relationship, total time living together?__ $\mathrm{yr}_{\ldots} \ldots \mathrm{mo}$ )

18. Are (were) you legally married to this person? Yes No NA

19. How satisfied are (were) you with your relationship? Circle only one answer.

1. extremely satisfied

2. mostly satisfied

3. somewhat satisfied

4. not satisfied, but not really dissatisfied

5. somewhat dissatisfied

6. mostly dissatisfied

7. extremely dissatisfied

For Quest. 20 and 21, use the following code to describe the highest educational level attained by yourself and by partner according to the following scale.

1. attended grammar school 5. attended college or technical school

2. completed grammar school

3. attended high school

6. completed college

4. completed high school or equivalency

7. attended graduate school

8. completed graduate degree

20. Self

$\begin{array}{llllllll}1 & 2 & 3 & 4 & 5 & 6 & 7 & 8\end{array}$

21. Partner 12345678 
22. What is the amount of income that your partner receives from all sources? Do not include your income in this amount.
1. under $\$ 500$
5. $\$ 6001-10000$
9. $\$ 35001-50000$
2. $\$ 501-1500$
6. $\$ 10001-15000$
10. $\$ 50001-65000$
3. $\$ 1501-3000$
7. $\$ 15001-25000$
11. over $\$ 65000$
4. $\$ 3001-6000$
8. $\$ 25001-35000$
12. I have no idea

23. How do (did) you and your partner combine incomes? Circle one.
1. not at all
2. partially
3. totally

The next three questions ask information on children who spend (spent) some amount of time in your household with you and your partner. Check NA if not applicable.

24.

$$
\text { Mine only }
$$

Partner's only

Ours together NA

25. ages

26. $\%$ of time living in

household

Who has (had) more say in your relationship in the following areas?

Put a check on the line in the appropriate place using this scale:

27. Handling of

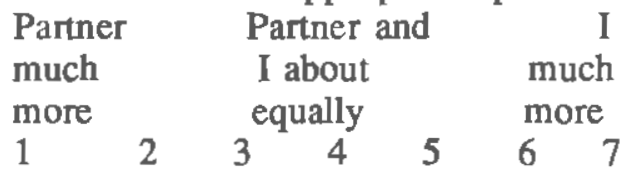

28. Matters of finances?

29. Religious recreation?

30. Demonstrations of affection?

31. Friends?

32. Sexual

relations?

33. Correct or proper behavior?

34. Ways of dealing with parents? or in-laws?

35. Amount of time spent together?

36. Household tasks?

37. Leisure time interests?

38. Career decisions? 
Who has the final say in making the following decisions ? Put a scale:

check on the line in the appropriate place using the following

39. Whether to move

\begin{tabular}{|c|c|c|}
\hline $\begin{array}{l}\text { Partner } \\
\text { always }\end{array}$ & & $\begin{array}{l}\text { Neithe } \\
\text { mor }\end{array}$ \\
\hline 2 & 3 & 4 \\
\hline
\end{tabular}

to another city,

state or country?

40. How much money to

spend on enter-

tainment/hobbies?

41. Whether or not

I work outside

of the home?

42. Where to go

on vacation?

Answer the next set of questions (43 through 59) by using the following code. Circle the appropriate number.

1. strongly agree

2. mostly agree

5. somewhat disagree

3. somewhat agree

6. mostly disagree

4. neither agree nor disagree NA not applicable

43. My partner has assumed more household responsibilities since I started going to college. $1234567 \mathrm{NA}$

44. Being with my partner makes (made) it easier for me to attend school. $1234567 \mathrm{NA}$

45. My panner has (had) a positive attitude towards my being in school. $1234567 \mathrm{NA}$

46. My partner perceives(d) my educational goals as a threat to our relationship. $1234567 \mathrm{NA}$

47. My schooling has (had) been the source of many arguments or disagreements with my partner. $12 \begin{array}{llllll}1 & 3 & 4 & 6 & 7 & \text { NA }\end{array}$

48. I feel I am (was) "in a rut" in this relationship. 1234567

49. I get (got) discouraged trying to make my relationship work out. 1234567

50. I consider(ed) my relationship situation to be as pleasant as it should be. 1234567

51. My partner gets (got) me badly flustered and jittery. 1234567

52. I have made (made) a success of my relationship so far. 1234567

53. The future of this relationship looks (looked) promising. 1234567 NA 
54. I am (was) really interested in my partner. 1234567

55. I get (got) along well with my partner. 1234567

56. My relationship helps (helped) me with the goals I have set for myself. 1234567

57. My partner lacks (lacked) respect for me. $\begin{array}{lllllll}1 & 2 & 3 & 4 & 5 & 67\end{array}$

58. I worry (worried) a lot about my marriage or relationship. 1234567

59. I think this relationship gets (got) more difficult for me every year. 1234567

Most persons have disagreements in their relationships. Please indicate below the approximate extent of agreement or disagreement between you and your partner for each item on the following list.

$\begin{array}{llllll}6 & 5 & 4 & 3 & 2 & 1\end{array}$

Almost Almost

Always Always Occasionally Frequently Always Always Agree Agree Disagree Disagree Disagree Disagree

$$
\begin{array}{llllll}
6 & 5 & 4 & 3 & 2 & 1
\end{array}
$$

60. Handling of Family Finances

61. Matters of Recreation

62. Religious Matters

63. Demonstrations of Affection

64. Friends

65. Sexual Relations

66. Conventionality (correct or proper behavior)

67. Philosophy of Life

68. Ways of Dealing with Parents or In-laws

69. Aims, Goals, and Things Believed Important

70. Amount of Time Spent Together

71. Making Major Decisions

72. Household Tasks

73. Leisure Time Interests and Activities 
74. Career Decisions

For the following questions $75-81$ please indicate the amount of time that this happens in your relationship. Circle the appropriate number according to the following code:

$\begin{array}{llllll}1 & 2 & 3 & 4 & 5 & 6\end{array}$

All the Most of More often

Time the time than not Occasionally Rarely Never

75. How often do (did) you discuss or have you considered divorce, separation or terminating your relationship? 1233456

76. How often do (did) you or your partner leave the house after a fight? 123456

77. In general how often do (did) you think that things between you and your partner are going well? 123456

78. Do (did) you confide in your partner? 1223456

79. Do (did) you ever regret that you married (or lived together)? $123456 \mathrm{NA}$

80. How often do (did) you and your partner quarrel? 123456

81. How often do (did) you and your partner "get on each others nerves"? 123456

82. Do (did) you kiss your mate? Circle one of the following

1- Never, 2- Rarely, 3- Occasionally, 4- Almost Every Day, 5-Every Day

83. Do you and your partner engage in outside interests together? Circle one of the following

1- None of them, 2-Very few of them, 3- Some of them, 4- Most of them, 5- All of Them

How often would you say the following occur between you and your partner? Circle one number according to the following code:

$\begin{array}{cccccc}1 & 2 & 3 & 4 & 5 & 6 \\ \text { Less than } & \begin{array}{c}\text { Once or } \\ \text { Once a }\end{array} & \begin{array}{c}\text { Once or } \\ \text { Twice a }\end{array} & \text { Twice a } & \text { Once a } & \text { More } \\ \text { Month } & \text { Month } & \text { Week } & \text { Day } & \text { Often }\end{array}$

84. Have a stimulating exchange of ideas 123456

85. Laugh together 123456

86. Calmly discuss something $\quad \begin{array}{llllll}1 & 2 & 3 & 4 & 5 & 6\end{array}$

87. Work together on a project 123456

There are somethings about which couples sometimes agree and sometimes disagree. Indicate if either item below caused differences of opinions or were problems in your relationship during the past few weeks. (Check one of the following). 
88. Being too tired for sex

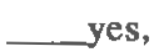
no, NA

89. Not showing love

yes, no, NA

90. The dots on the following line represent degrees of happiness in your relationship. The middle point, "happy," represents the degree of happiness of most relationships. Please circle the dot which best describes the degree of happiness, all things considered of your relationship.

\begin{tabular}{|c|c|c|c|c|c|c|}
\hline 1 & 2 & 3 & 4 & 5 & 6 & 7 \\
\hline . & . & . & . & . & . & . \\
\hline $\begin{array}{l}\text { Extreme- } \\
\text { ly }\end{array}$ & Fairly & $\begin{array}{r}A \\
\text { little }\end{array}$ & & Very & $\begin{array}{l}\text { Extreme- } \\
\text { ly }\end{array}$ & \\
\hline Unhappy & Unhappy & Unhappy & Happy & Happy & Happy & Perfec \\
\hline
\end{tabular}

91. Which of the following best describes how you feel (felt) about the future of your relationship? Check only one.

- I want desperately for my relationship to succeed, and would go to almost any length to see that it does. I want very much for my relationship to succeed, and will do all that I can to see that it does.

- I want very much for my relationship to succeed and will do my fair share to see that it does.

_ It would be nice if my relationship succeeded, but I can't do much more than I am doing now to help it succeed.

_ It would be nice if it succeeded, but I refuse to do any more than $I$ am doing now to keep the relationship going.

My relationship can never succeed, and there is no more that I can do to keep the relationship going.

92. Thinking back to January of 1989 , and using the same instructions you are using now, (those found on Page 3, \#10) is the partner in the relationship you are reporting on today, the same one as before, or are you reporting on a relationship with another person?

Please check the correct response, then continue as directed.
a. same person
b. (go to \#93) (go to \#101)
c. __don't know (go to \#97)

93. If your answer to question 92 is b. "another person", do you think this relationship is (was) different from the one you reported on in January of 1989 ? Please check only one. Yes No Don't know

94. How do you think it is different? Please comment. 
95. How do you think the partners in the two relationships are (were) similar to each other?

96. How do you think the partners are different from each other?.

go to \# 101

97. If your answer to Question 92 was a. "the same person", do you think this relationship is (was) different from the one you reported on in January of 1989 ? Please check only one. __ Yes __ No _ Don't know __ NA

98. In what ways is your relationship different? Please comment.

99. Do you think your partner is different now than in 1989 ? _ Yes___No __Don't Know __ Not Applicable

100. In what ways is your partner different now than in 1989 ? Please comment.

101. On a scale of 1 to 7 with 1 being very negative, 7 being very positive, and 4 being not negative and not positive, circle how good you felt about yourself being in the relationship reported on in January of 1989.

$\begin{array}{lllllllll}1 & 2 & 3 & 4 & 5 & 6 & 7 & \text { NA }\end{array}$

102. On a scale of 1 to 7 with 1 being very negative, 7 being very positive, and 4 being not negative and not positive, circle how good you feel (felt) about yourself being in the relationship that you are reporting on now. $1 \begin{array}{lllllllllll}1 & 2 & 3 & 4 & 5 & 6 & 7 & \mathrm{NA}\end{array}$

103. Do you think that your relationship with your partner changed during the course of your undergraduate education? __ Yes _ No ___ don't Know __ NA

104. In what ways did it change? Please comment.

105. Who do you think should have more say in decisions that affect your intimate relationships? Circle your answer.
1. Partner much more
5. I somewhat more
2. Partner mostly
6. I mostly
3. Partner somewhat more
7. I much more
4. Partner and I about equally

106. Since first entering college, have you attended school continuously without interruption or time out? Please circle one. Yes No 
107. If you resumed your college education after having left college for a period of time, please indicate the amount of time that elapsed between the time you first left college and when you began to take courses again? yrs.

108. How many credits have you earned in the past $31 / 2$ years (since January, 1989, 7 semesters and summer sessions)? undergraduate credits graduate credits.

109. How many courses have you taken in the past $31 / 2$ years (since January, 1989, 7 semesters and summer sessions)? undergraduate courses graduate courses

110. When did you last take coursework? Fill in month/year

111. What best describes your educational status as of Sept. 1992 ? Please circle all that apply.

1. Permanently withdrawn from school with no plans to reenter.

2. Temporarily withdrawn from school, will resume someday.

3. Temporarily withdrawn from school, will begin again shortly.

4. Taking undergraduate coursework.

5. Completed my educational goals, or certificate program.

6. Completed my Bachelors Degree.

7. Taking graduate coursework.

8. Completed a graduate degree.

112. What has made it difficult for you to remain in school, or caused your withdrawal from CCE? Please circle all that apply.

a. family responsibilities

b. relationship problems

c. illness (self/family)

d. no interest/motivation

e. not enough support at home

f. not enough support from COE g. financial problems

h. child care

i. transportation

j. not enough time

k. didn't like CCE
1. employment

m. lack of classes

n. cost of classes

o. time of classes

p. didn't fit in

q. other

(please specify)

113. How have you financed your education? Check all that apply. personal savings money from employment personal loans other (Please specify) financial aid grants and loans employer reimbursement scholarships

In order for my research to be valid, I need to have identical groups Please write the last 4 digits of your student ID (usually SS number) in reverse order in the spaces provided below. If for example, your ID\# is 681723549 , you would write $944 \quad 5 \quad 3$ in the spaces provided.

114. Code number 
Listed below are a number of events which sometimes bring about change in the lives of those who experience them. Please check only those events which have been experienced during 1989, 1990, 1991 or 1992.

115. Marriage

116. _- Separation from spouse/ partner (due to conflict)

117. _Divorce

118. ___Reconciliation with spouse/partner

119. __ Major change in number of arguments with spouse/partner

120. _ Detention in jail or comparable institution

121. ___Engagement

122. ___ Moving in with lover

123. _Breaking up with lover

124. ___Reconciliation with lover

125. ___Leaving home for first time

126. __ Death of spouse/partner, ___mother, __father, ___child, brother/sister, _-grandmother/grandfather, close friend, __other (please specify)

127. _ Serious illness or injury (self), __ spouse/partner, mother, _.._father,___brother/sister,

_-_ grandmother/grandfather

128. _Permanent disability (self), spouse/partner, child

129. —Changed work situation, different work responsibility, hours, conditions (self), _spouse/partner

130. _Being fired or let go from job (self), __spouse/partner

131. __Unemployed (self), __spouse/partner

132. __ Retirement from work (self), ___spouse/partner

133. __ Begin new job (self), __ spouse/partner

134. __ Foreclosure of mortgage or loan

135. __ Outstanding personal achievement

136. _....Minor law violations

137. ___Court appearances for child support/spousal support 
138. Pregnancy

139. Miscarriage, Abortion

140. __Ending of formal schooling

141. __Beginning new academic or training program

142. __ Change of residence

143. Separation from spouse/partner (due to work, travel, school, etc)

144. ___ Sexual harassment (at job, school, elsewhere)

145. _ Sexual assault (rape/ attempted rape) by stranger, by acquaintance, __by spouse/lover

146. _._Physical assault by stranger, by spouse/lover

147. ___ Robbery or mugging

148. __Awareness of childhood sexual abuse by non-family member by family member

149. ___ Sexual difficulties

150. __C Change in residence

151. _ Trouble with employer

152. __ Trouble with in-laws

153. __ Major change in financial status

154. _ Major change in living conditions

155. _ Major change in closeness of family members

156. _ Gaining a new family member (birth, adoption, family member moving in)

157. __ Major change in usual type and/or amount of recreation

158. __ Major change in sleeping habits

159. __ Major change in eating habits

160. Borrowing more than $\$ 50,000$ (buying home, business etc.)

161. Borrowing less than $\$ 50,000$ (buying car, furniture, school loan, etc)

162. Money in closed bank or credit union 
163. Homelessness

164. __ Daughter or son leaving home (due to marriage, coliege, work, etc.)

165. _ Counseling or Therapy for self, ___spouse/partner, ___child, couple (you and spouse/partner) __family

166. _ alcohol problems (self), spouse/partner, child, parent

Other experiences during 1989, 1990, 1991, 1992 which have had an impact on your life. Please list below.

167.

168.

169.

Additional comments or continuation of questions from previous pages.

Thank you very much for your time and effort in completing this survey. 
Appendix B

92 
Appendix B 


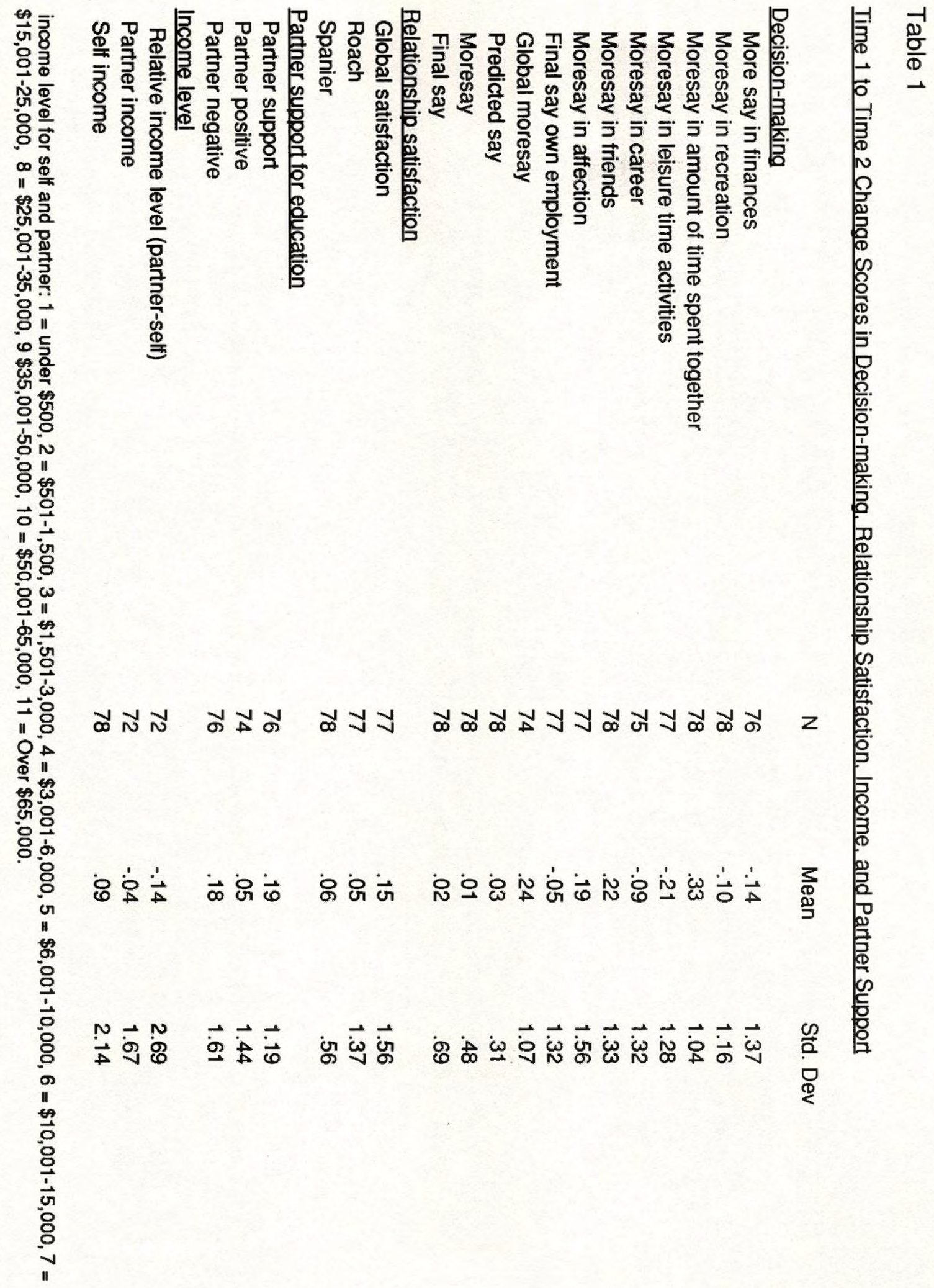




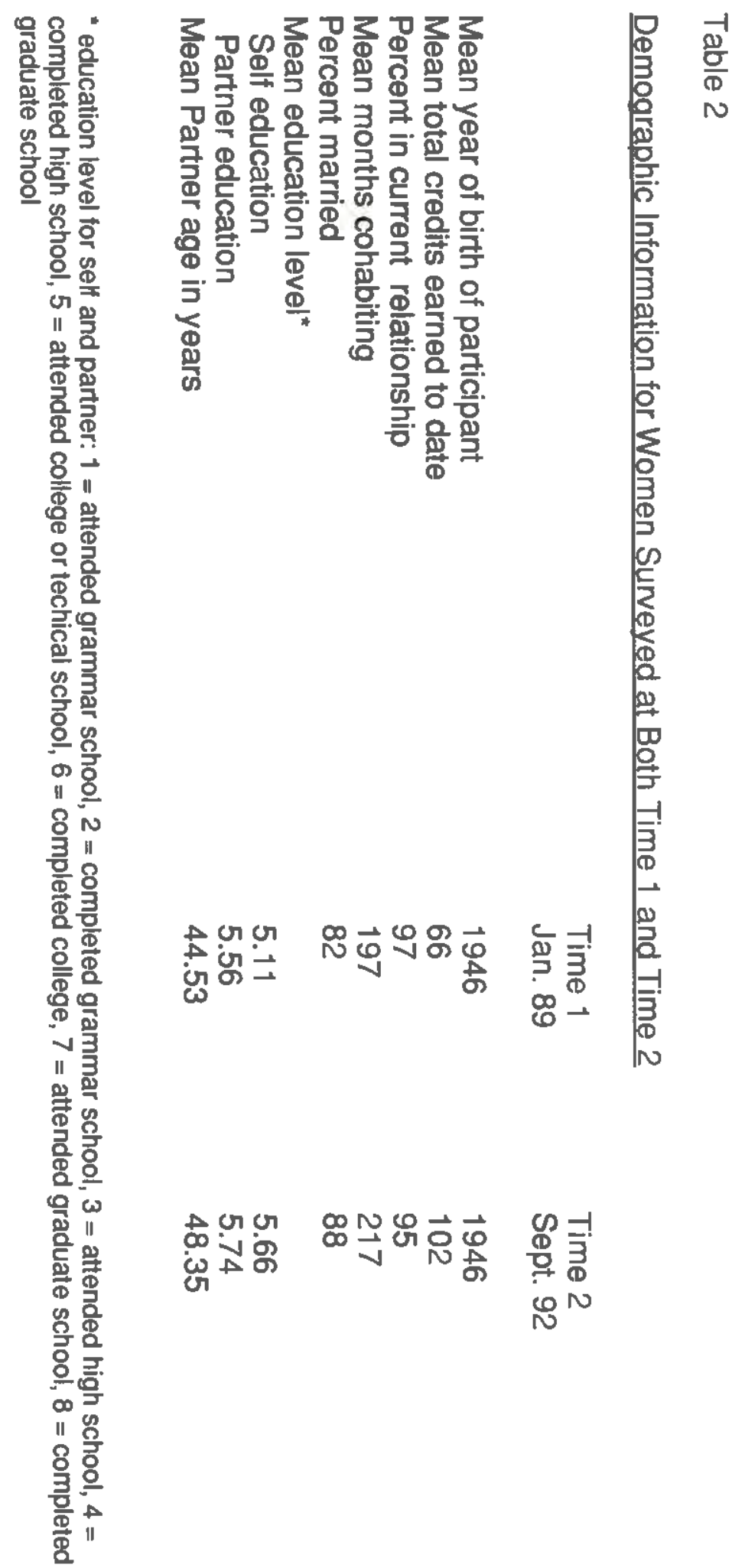




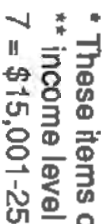

응을

8 in

$\infty \stackrel{\circ}{=}$

的点

势富

응

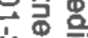

on $\frac{2}{8}$

$8 \overrightarrow{8}$

등

6 要

II 9

点舟

응

옹

'․ㅣㄱ

热官

ㅇㅇㅇ옹몽

10

용 8

iI 80

क $\omega \frac{1}{7}$

용

京就

ำ

$8 \omega$ क

80

$+8$

II $\rightarrow 9$

$Q \operatorname{si}$

홍

78

o $\frac{1}{1}$

응용

u

कs

8

$\frac{1}{1}$

8

$\infty$ Un MUN M M

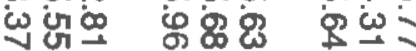

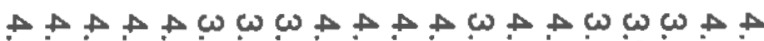

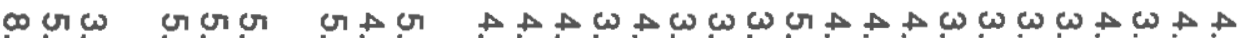

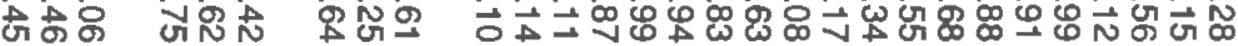

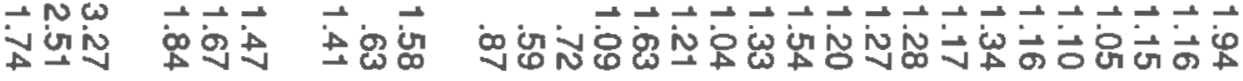

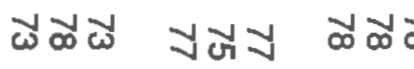

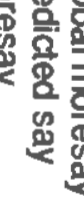

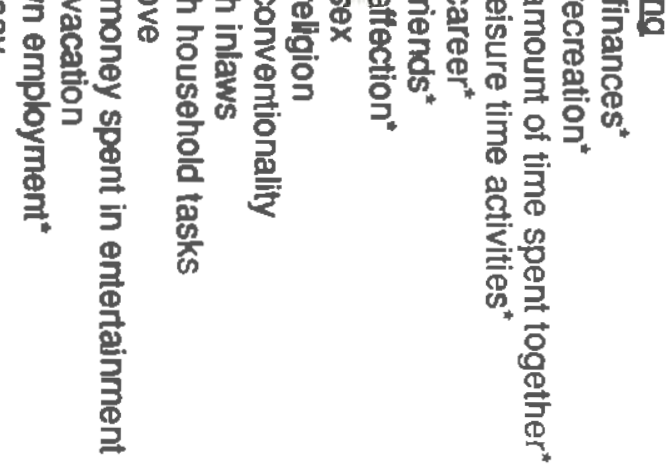

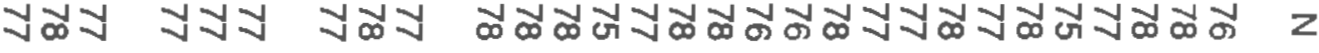

$z$

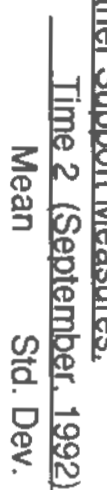

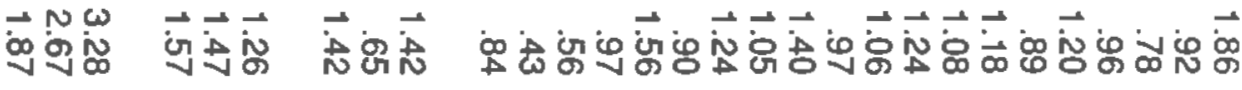




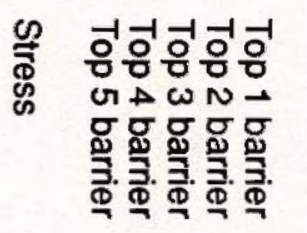

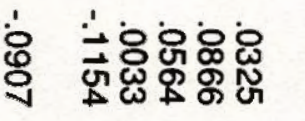

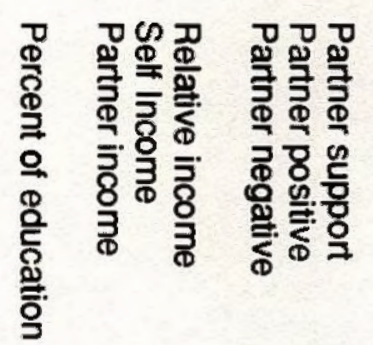

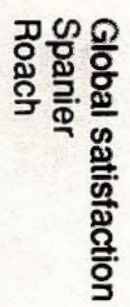

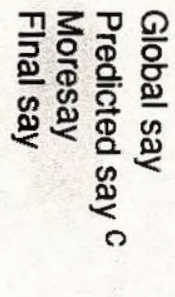

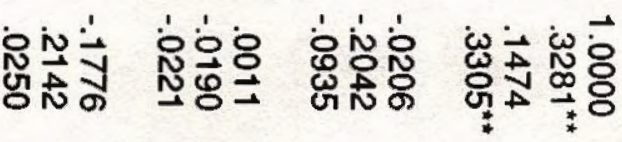

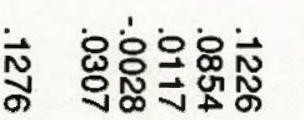

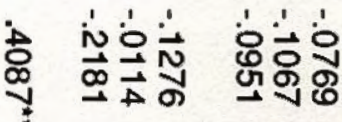

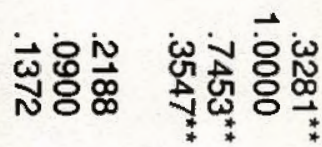

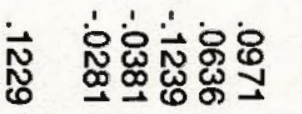

* 岁

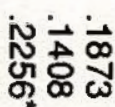

융용 点声吉

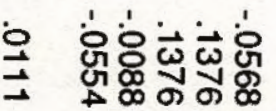

के ثี่

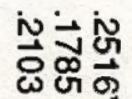

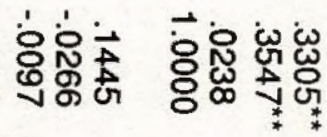

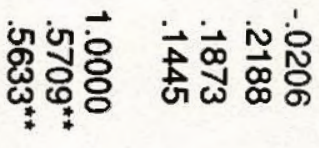

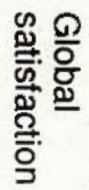

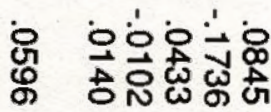

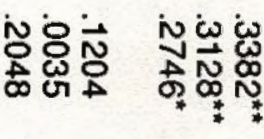

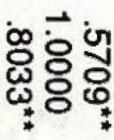

نं

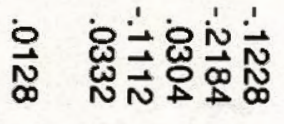

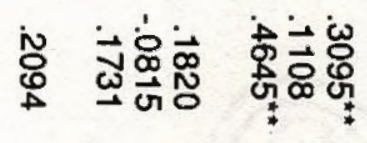

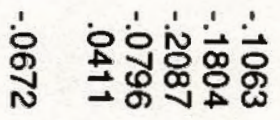

స్ 요요

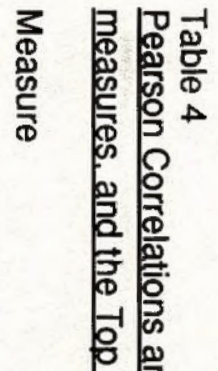

$\frac{0}{0}$
$\frac{0}{0}$
$\stackrel{0}{0}$

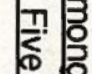

崖.

o

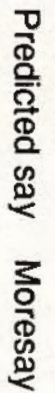

整官

高

(1)

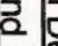

里

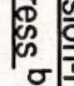

展

粱

象

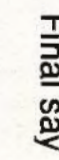

洯产

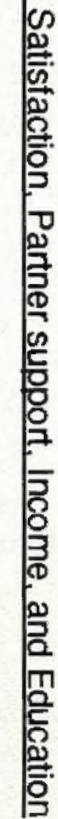




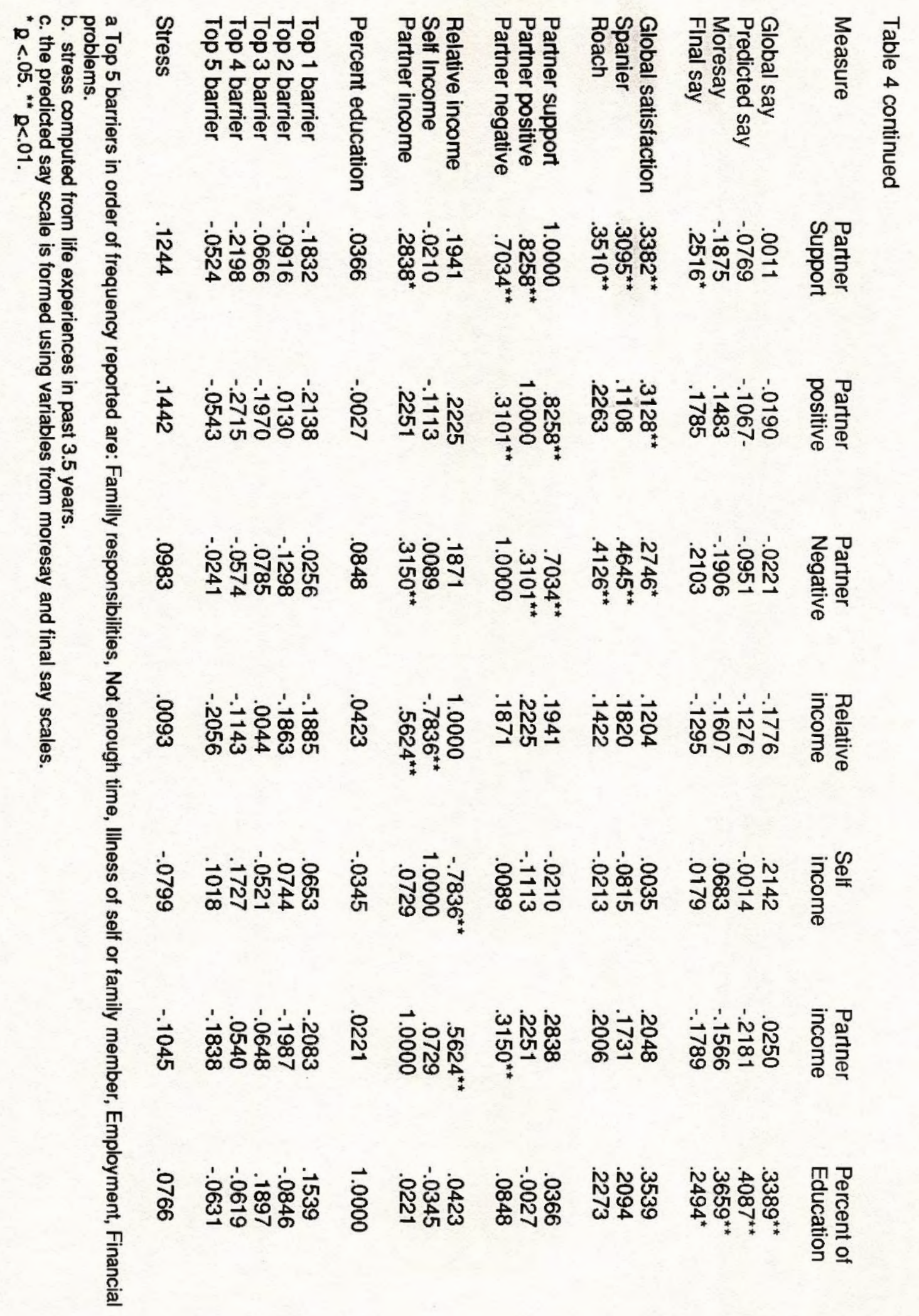



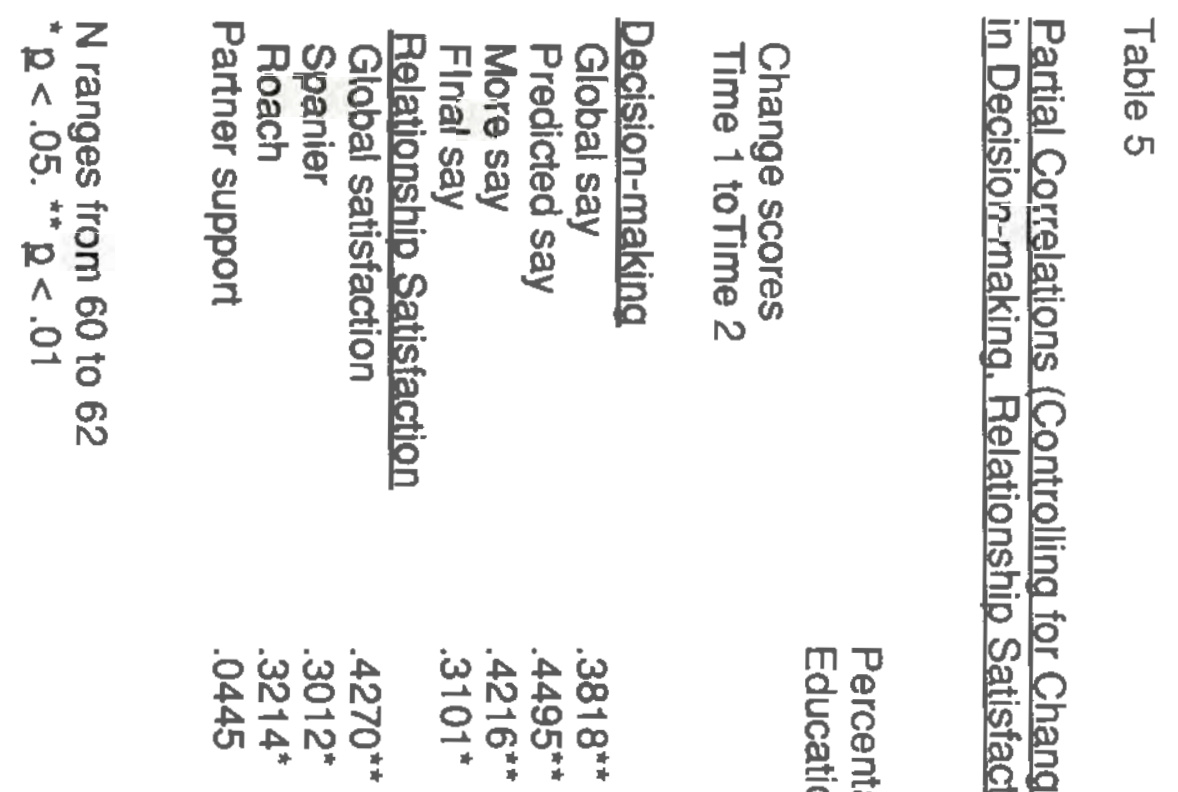

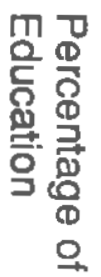

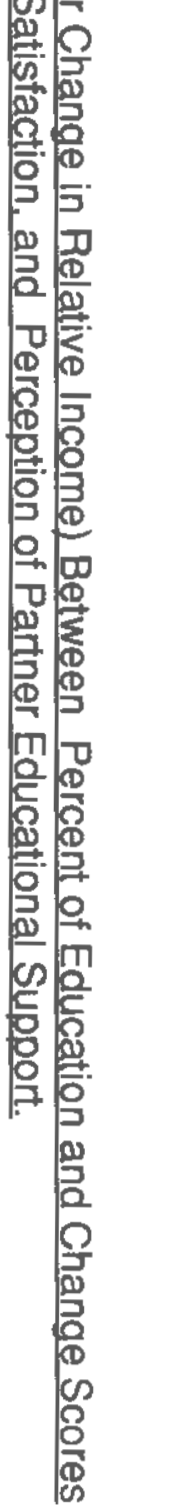




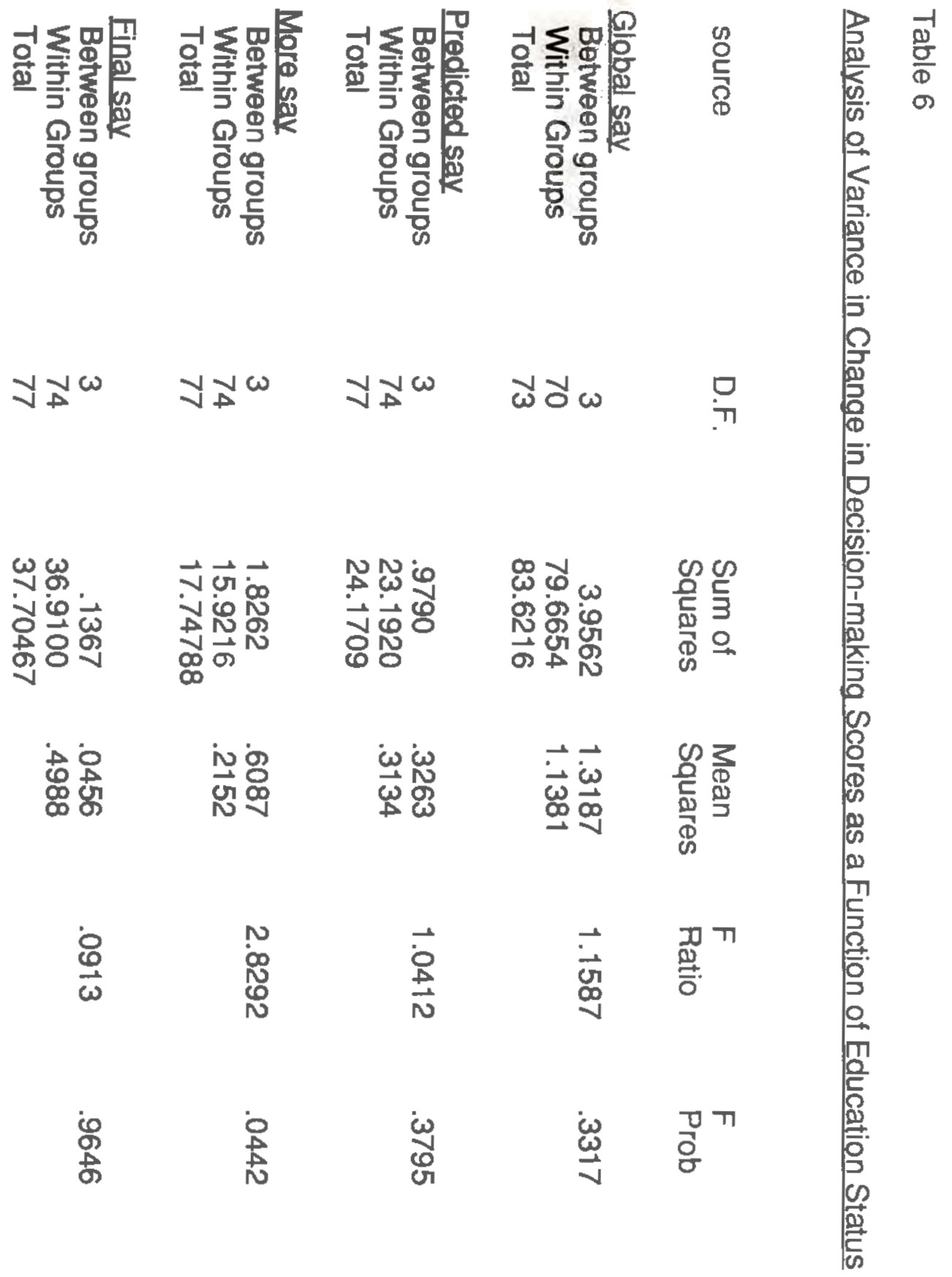




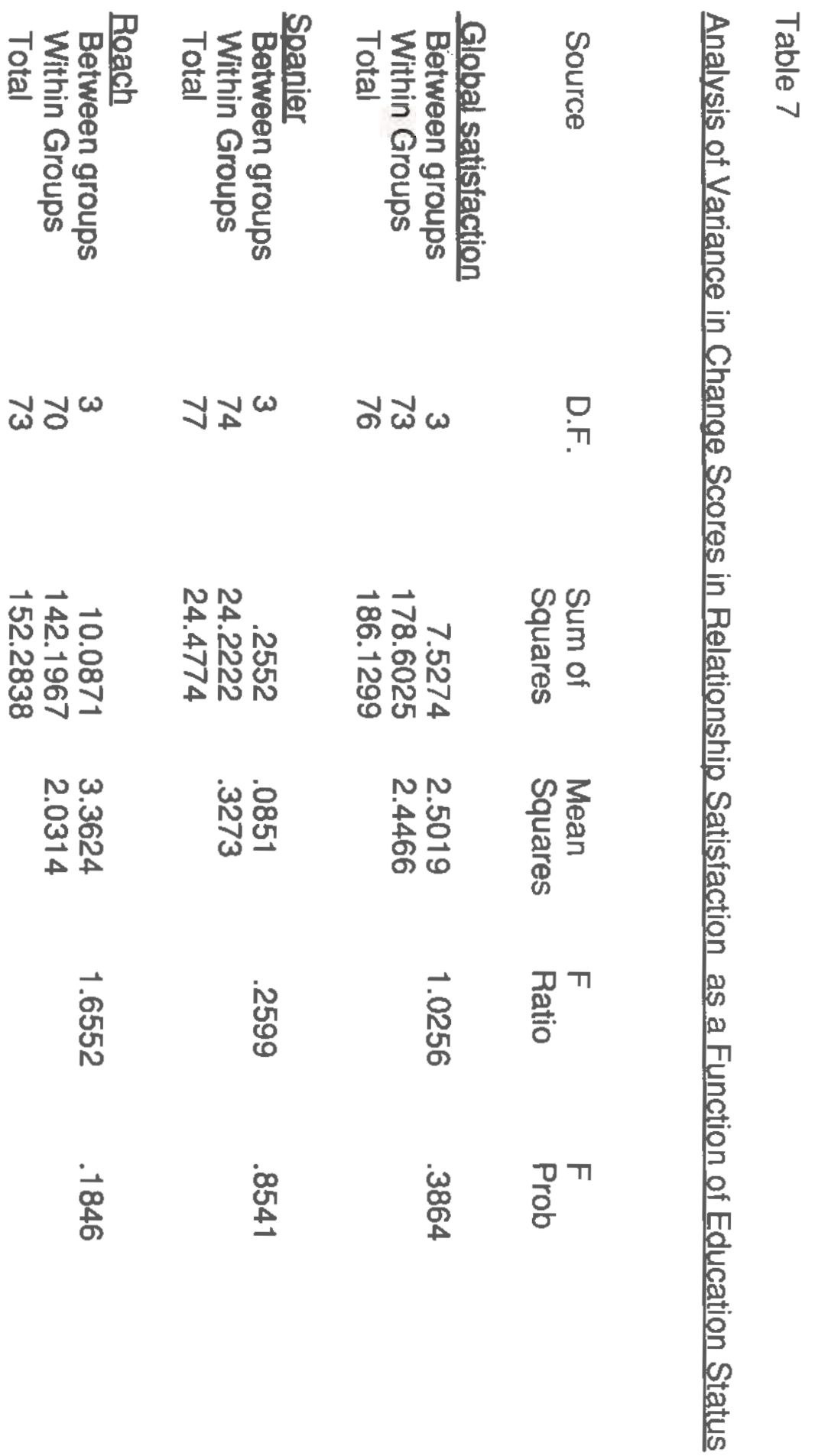




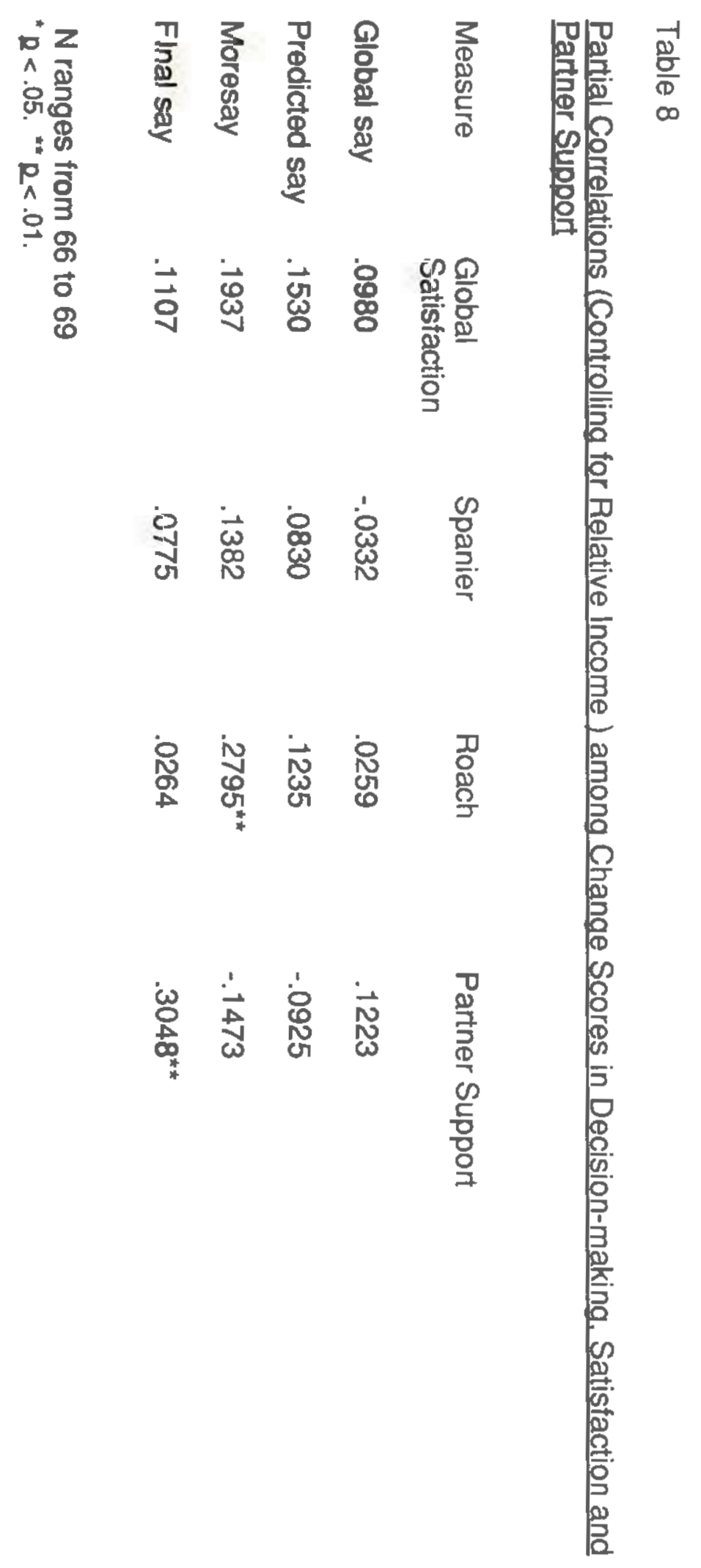



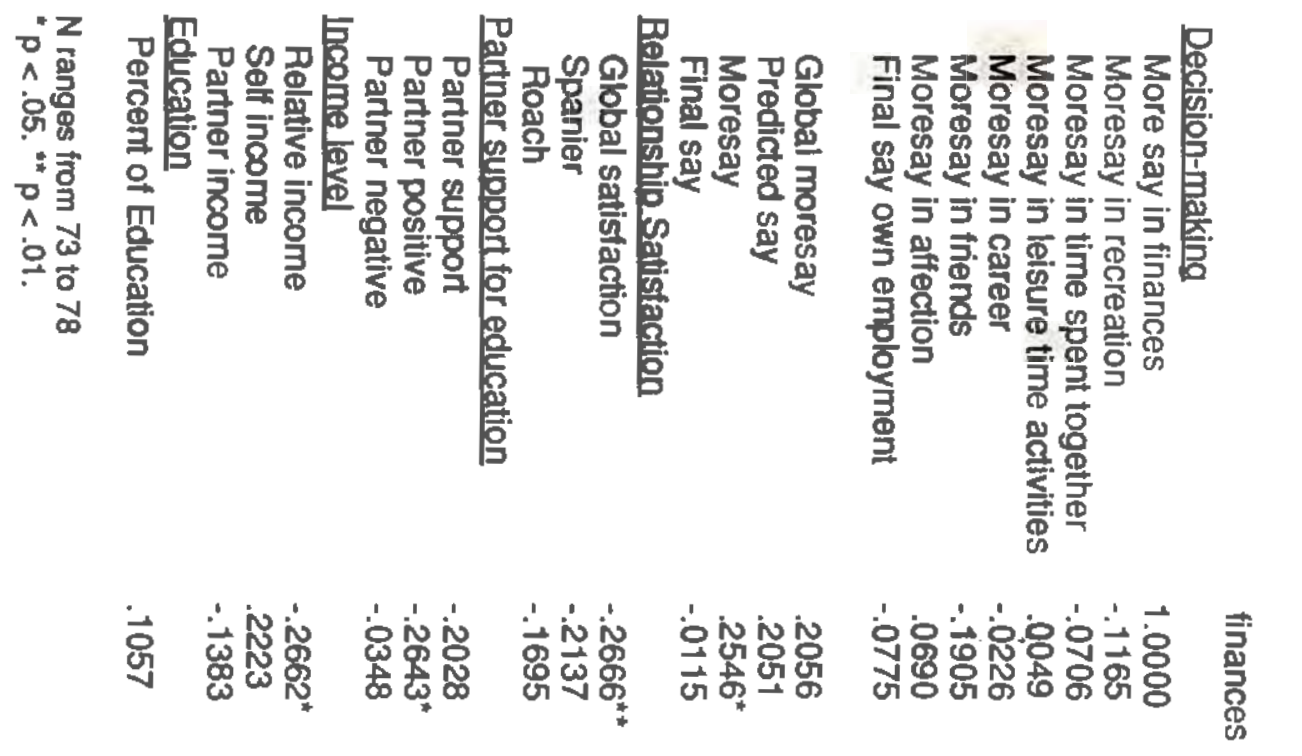

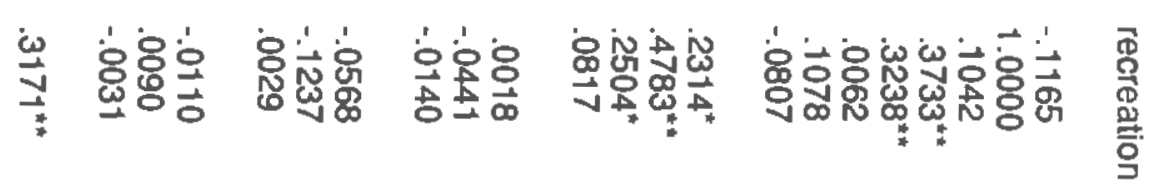

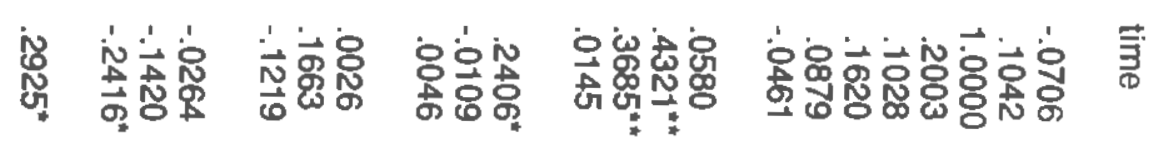

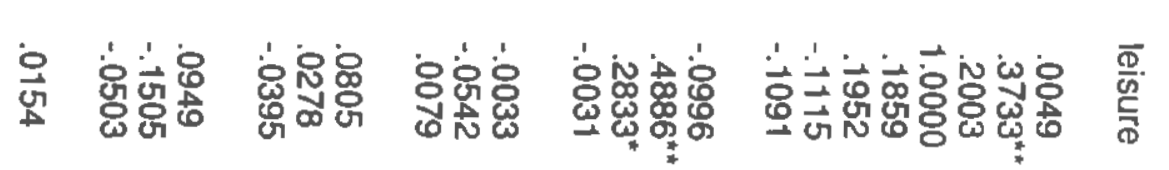

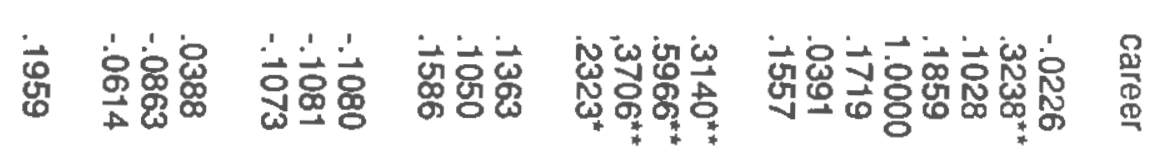

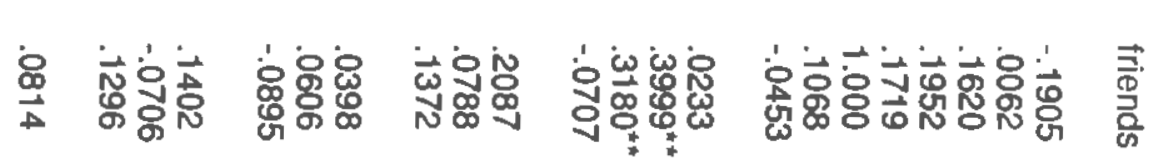

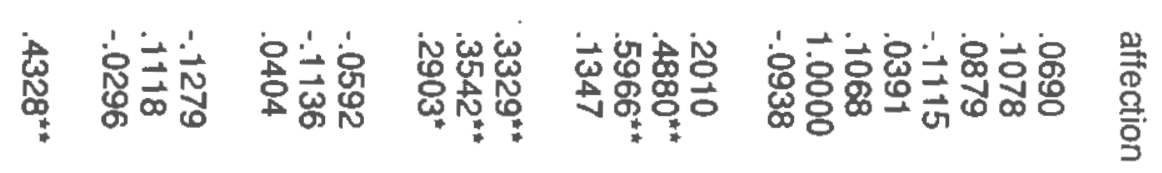

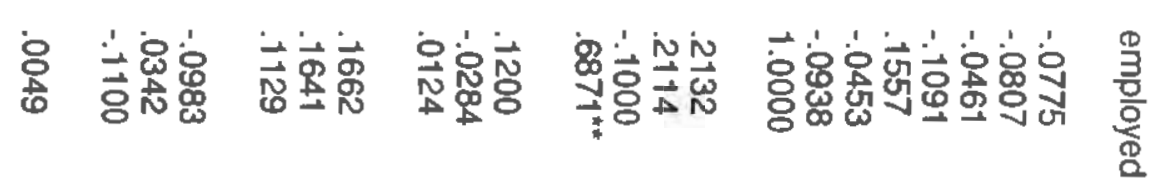

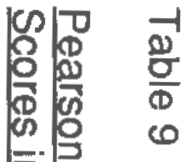

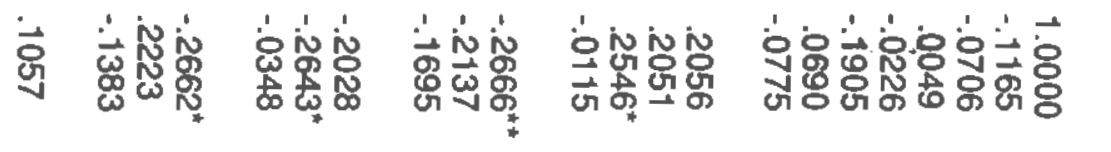

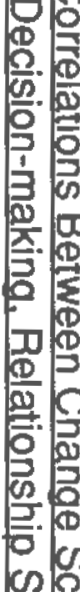

高

要

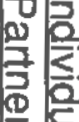

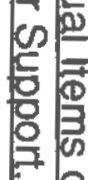

年

$\infty$

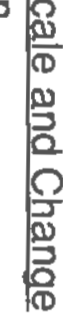



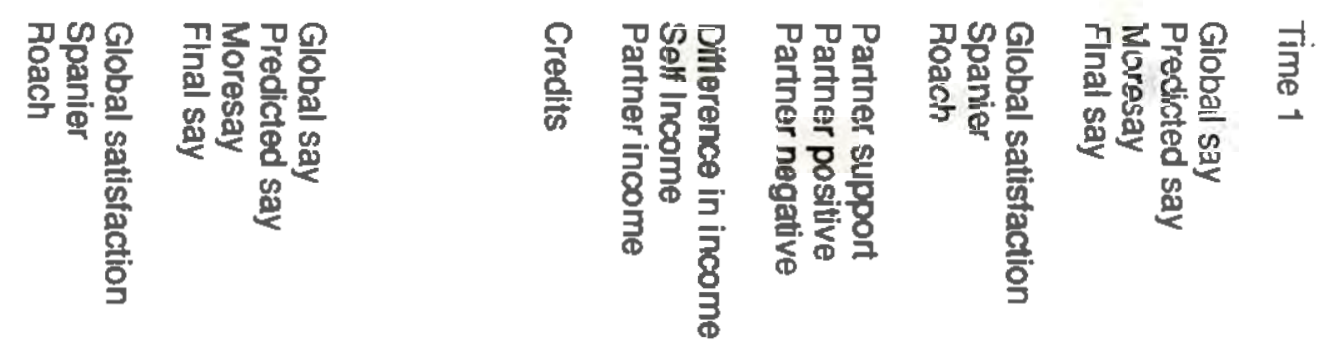

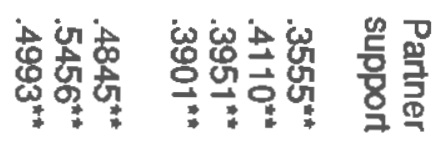

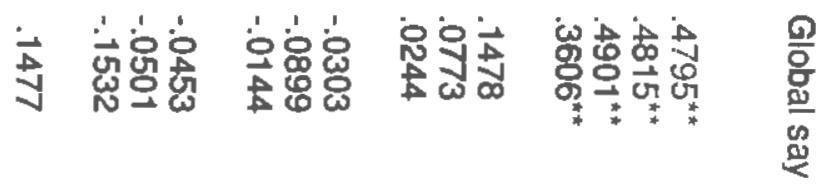

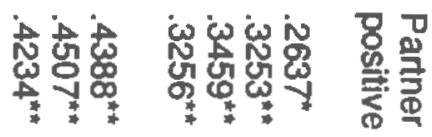

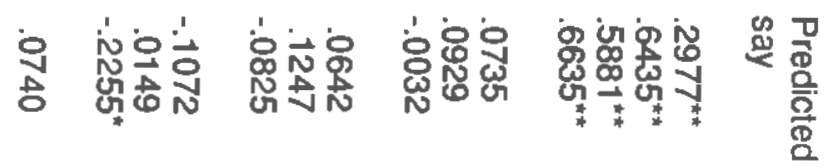

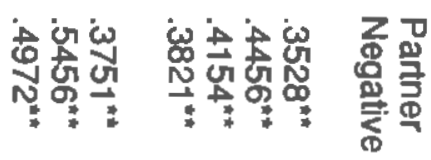

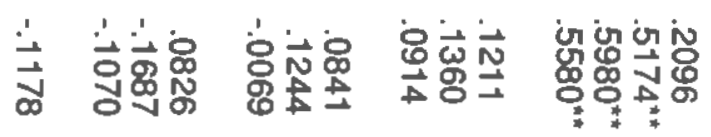

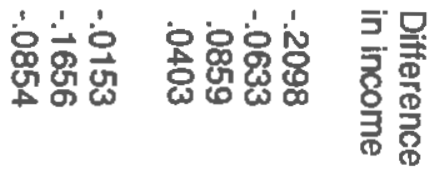

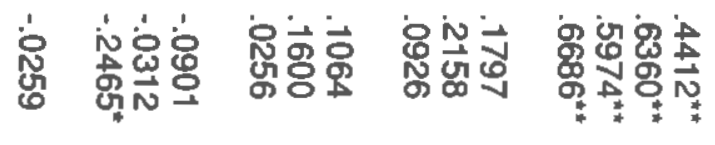

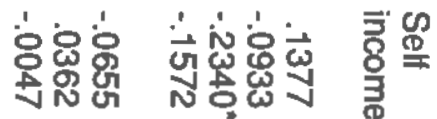

号

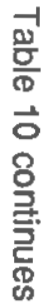

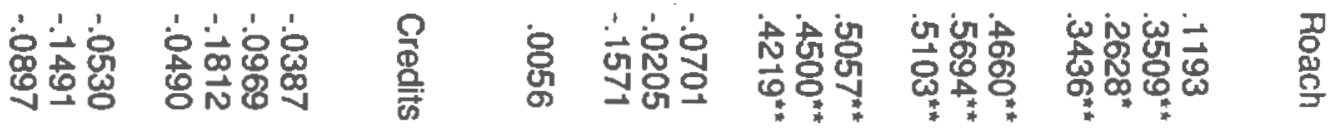

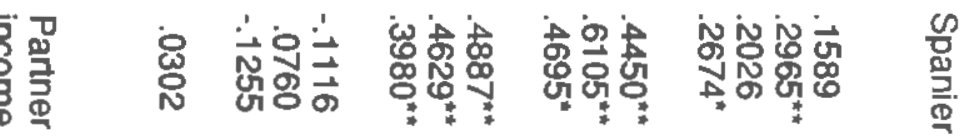

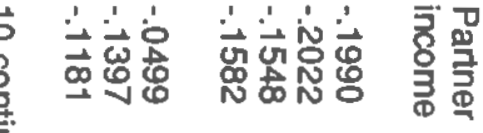

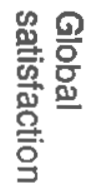




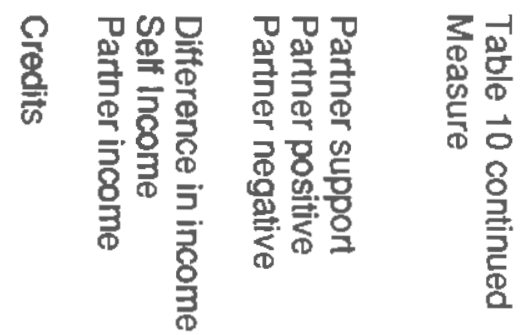

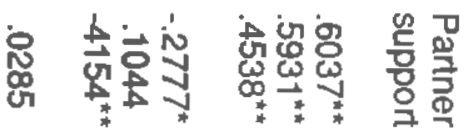

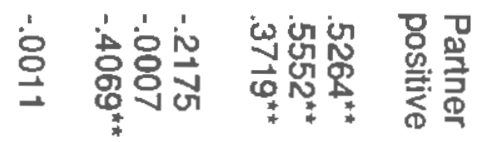

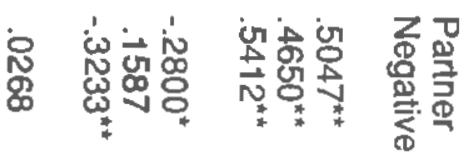

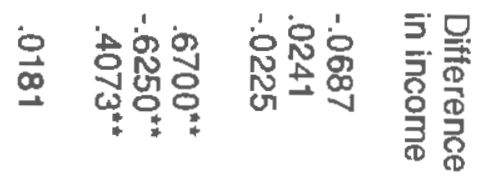

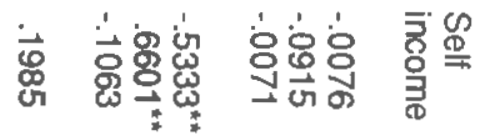

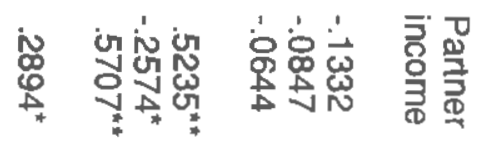

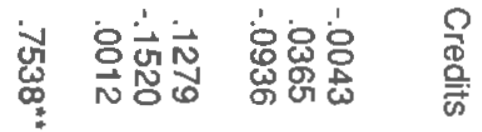




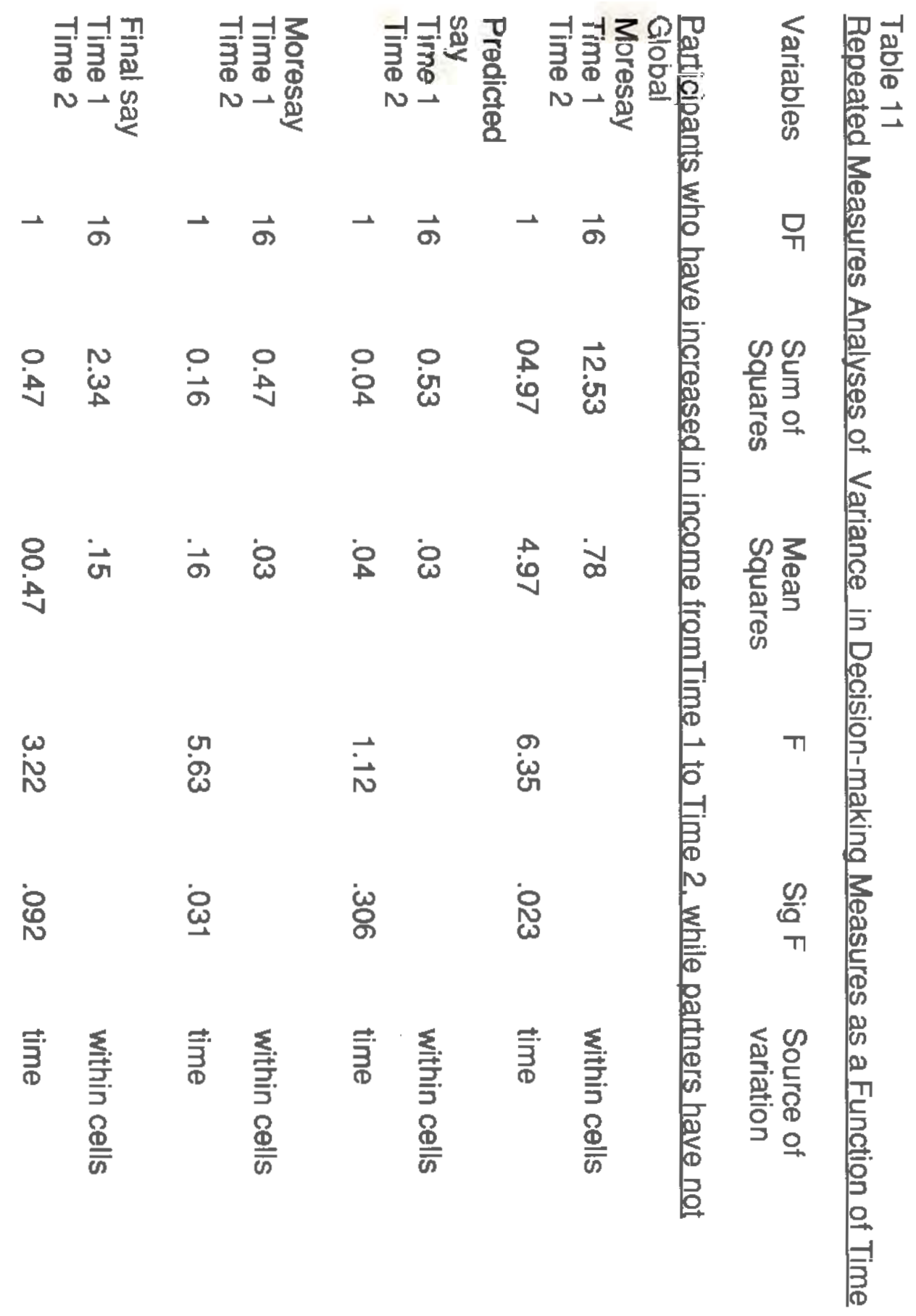




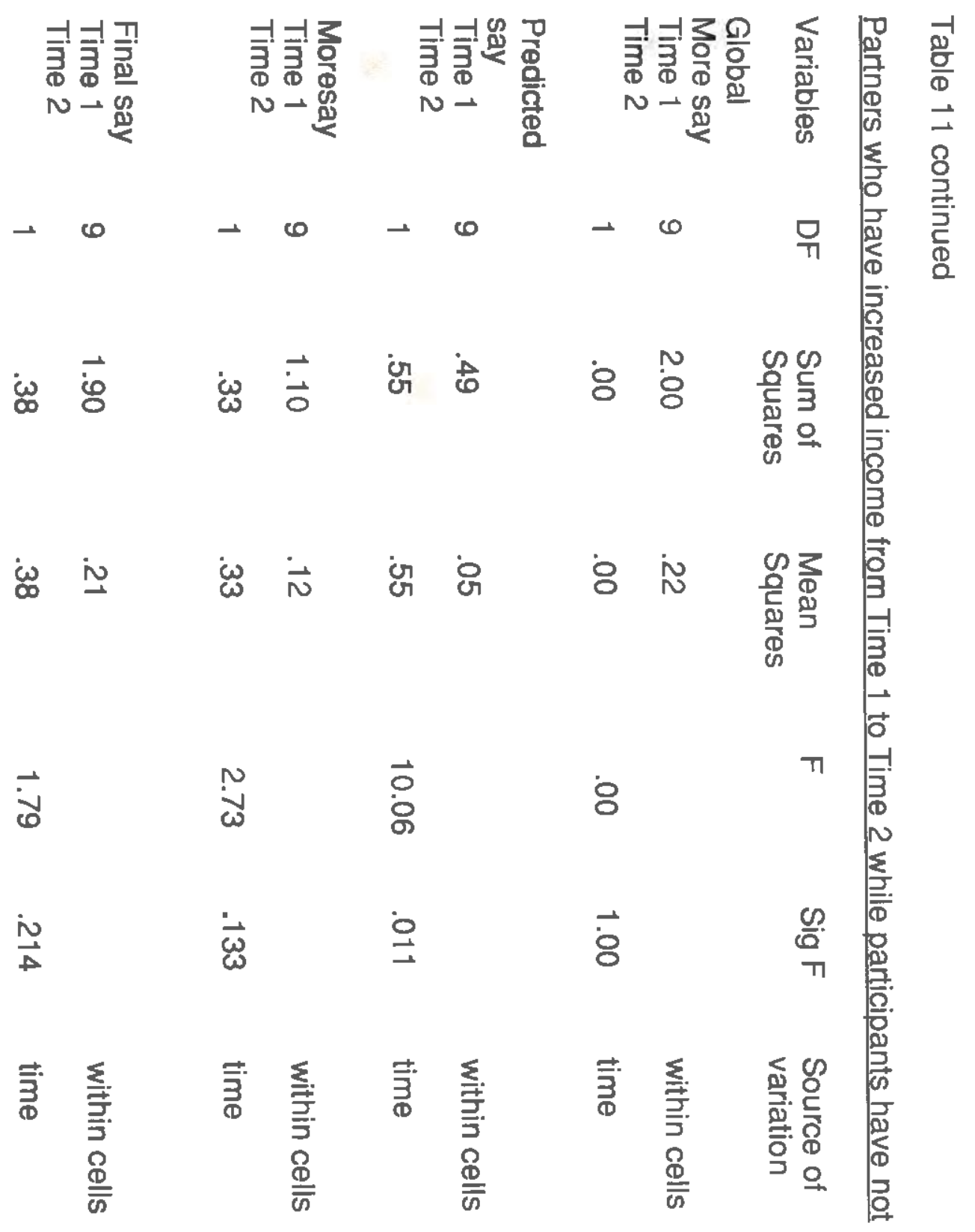




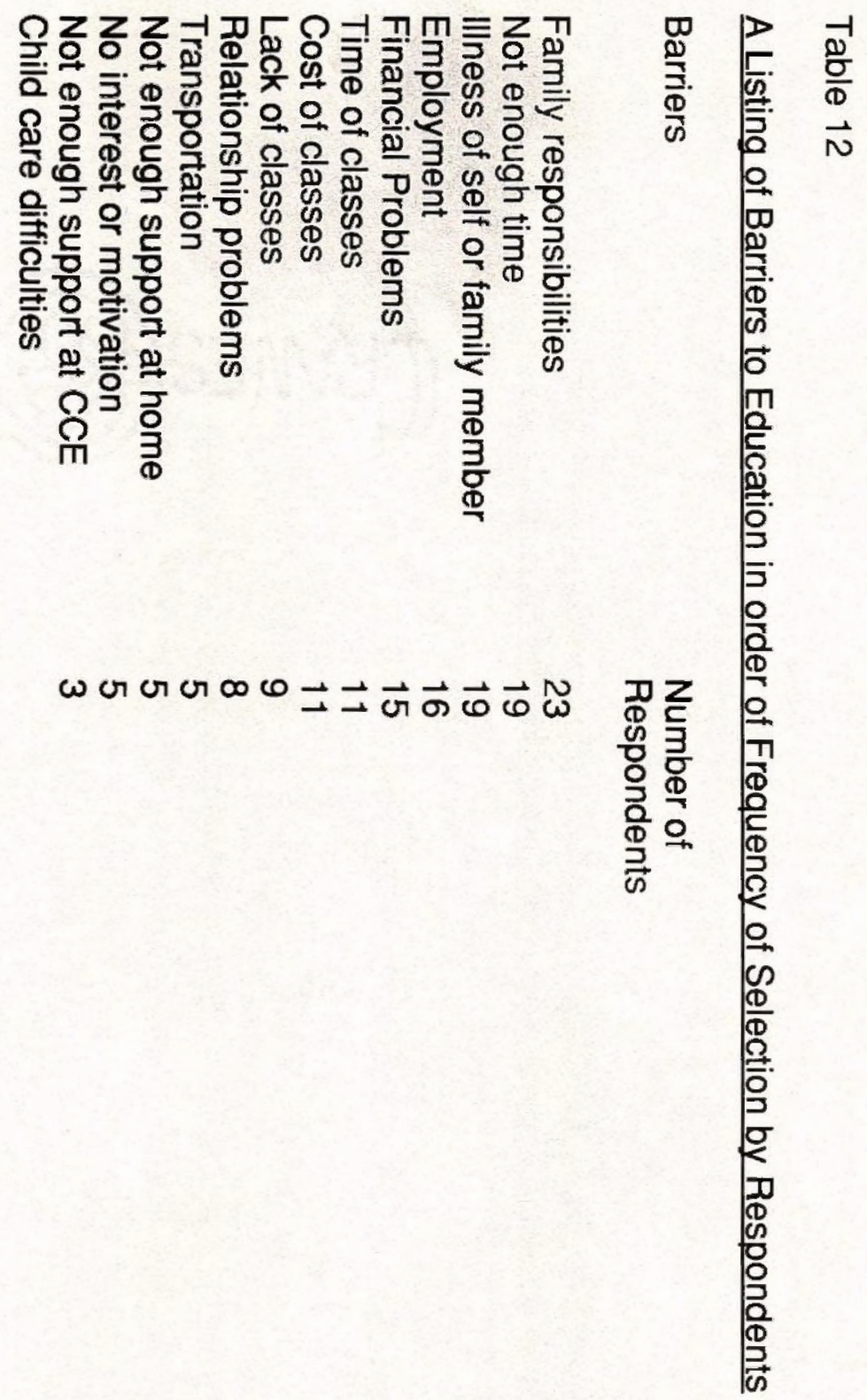




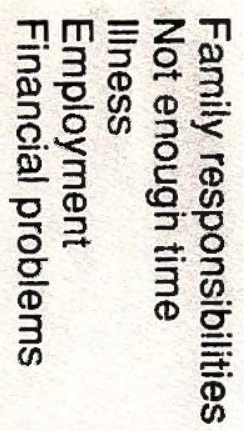

象整

엉욜 z

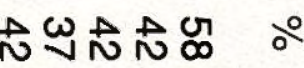

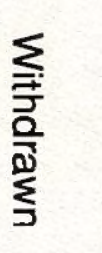

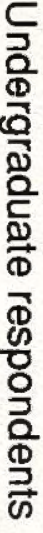

옹

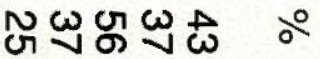

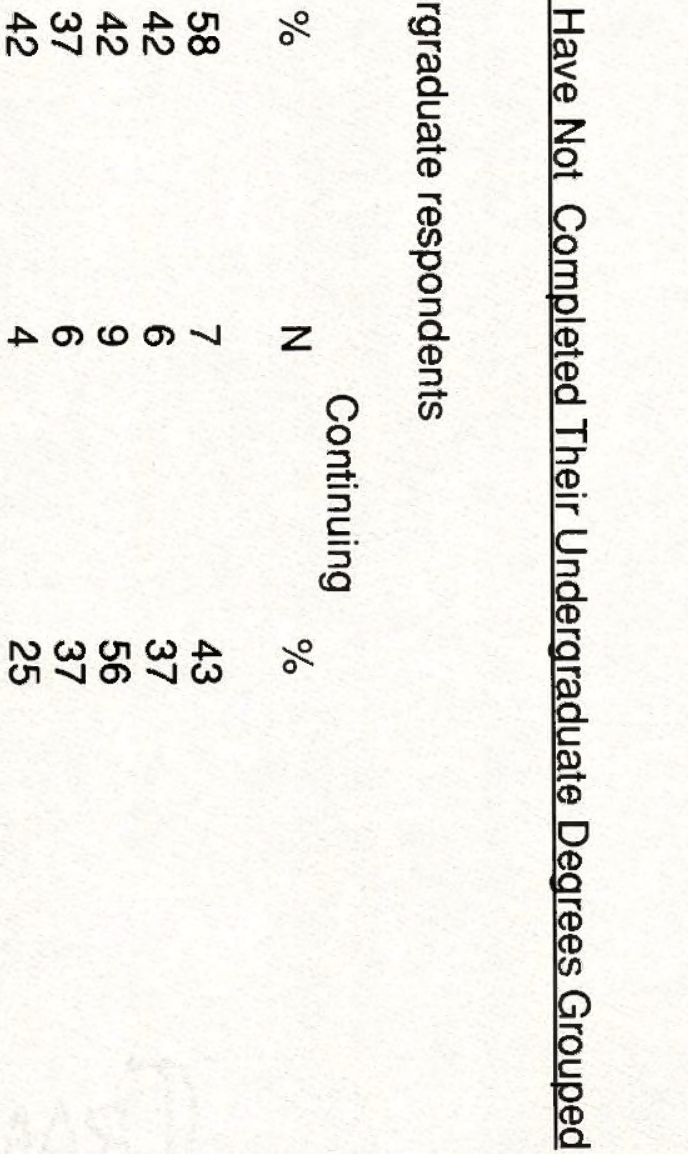

○े 


\section{BIBLIOGRAPHY}

Aida, Y. \& Falbo, T. (1991). Relationship between marital satisfaction, resources and power strategies. Sex Roles, 24, p.43-56.

Allen C. M., \& Straus, M. A. (1984). "Final say" measures of marital power: Theoretical critique and empirical findings from five studies in the United States and India. Journal of Comparative Family Studies, 15 (3), 329-344.

Altrocchi, J. \& Crosby, R.D. (1989). Clarifying and measuring the concept of traditional vs egalitarian roles in marriages. $\underline{\mathrm{Sex}}$ Roles, 20, 639-648.

Anderson, E.A. \& Leslie, L.A. (1991). Coping with employment and family stress: Employment arrangement and gender differences. Sex Roles, 24, 223-237.

Aneshensel, C.S. (1986). Marital and Employment role strain, social support and depression among adult women, in S.E. Hobfoll (Ed.). Stress. Social Support and Women (p. 99112). New York: Hemisphere Publishing Co.

Bandura, A. (1982). Self Efficacy Mechanism in Human Agency. American Psychologist, 37, 122-147.

Barrera, M. (1986). Distinctions between social support concepts, measures, and models. American Journal of Community Psychology, 14, 413-445.

Baruch, G. K. (1972). Maternal influences upon college women's attitudes towards women and work. Developmental Psychology, 6, 32-37.

Baruch, G. K., \& Barnett, R. C. (1979, November). If the study of midlife had begun with women. Paper presented at the meeting of the Gerontological Society meeting, Washington, D.C

Bean, J., \& Metzner B. (1985). Conceptual models of nontraditional undergraduate student attitudes. Review of Educational Research, 5, 485-540.

Bernard, J. (1971). The paradox of the happy marriage, in V. Gornick \& B. Moran, (Eds.), Women in Sexist Society: 
Studies in Power and Powerlessness. New York: Basic Books.

Bernard, J. (1981). The good provider role: Its rise and fall. American Psychologist, 36 (1), 1-12.

Billingham, R., \& Sack, A. R. (1987). Conflict tactics and the level of emotional commitment among unmarrieds. Human Relations, 40 (1), 59-74.

Blau, P.M. (1964). Exchange and Power in Social life. New York: Wiley \& Sons.

Blood R,. \& Wolfe D. (1960). Husbands and Wives: The

Dynamics of Married Living. Glencoe, Il. Press.

Blumstein, P., \& Schwartz, P. (1983). American Couples: Money Work, Sex. New York: Morrow.

Brownmiller, S. (1975). Against Our Will: Men. Women and Rape. New York: Simon \& Schuster.

Caldwell, M., \& Peplau, L. (1984). The balance of power in lesbian relationships. Sex Roles, 10, 587-99.

Campbell. A. (1980). The sense of well-being in America. New York: McGraw Hill.

Cardoza, D. (1991). College attendance and persistence among

Hispanic women: An examination of some contributing factors. Sex Roles, 24, 133-147.

Carroll, J. L., Volk, K. D., \& Hyde, J. S. (1985). Gender Differences in Sexual Behavior. Archives of Sexual Behavior, 14 (2) 131-39.

Cate, R. M., Lloyd, S. A., \& Henton, J. M. (1985). The effect of equity, equality, and reward level on the stability of students' premarital relationships. Journal of Social Psychology, 125 (6), 715-21.

Celebucki, C.C. (1990). Power and satisfaction in reentry women's intimate relationships. Unpublished Masters thesis, University of Rhode Island.

Chacon, M.A., Cohen, E.G., \& Strover, S. (1986). Chicanas \& Chicanos: Barriers to progress in higher education. In M.A. Olivas (Ed.), Latino College Students (pp. 296-324). New York: Teachers College Press. 
Chiriboga, D.A. \& Dean, H. (1977). Dimensions of stress:

Perspectives from a longitudinal study. Journal of Psychosomatic Research, 22, 47-55.

Chododrow, N. (1978). The Reproduction of Mothering.

Berkeley: University of California Press.

Clayton, R. R. (1979). The Family. Marriage and Social Change.

Lexington MA: D. C. Heath.

Clayton, D. E., \& Smith, M. M. (1987). Motivational typology of

women. Adult Education Ouarterly, 37, 90-104.

Cleary, P.J. (1980). A checklist for life event research. Journal of Psychosomatic Research, 24, 199-207.

Cochran, S. D., \& Peplau, L. A. (1985). Value orientations in

heterosexual relationships. Psychology of Women

Quarterly, 9, 477-488.

Cohen, J. (1969). Statistical Power Analysis for the Behavioral

Sciences. New York: Academic press.

Crimmins, E., \& Riddler, E. (1985). College enrollment trends,

1972-82. Educational Gerontology, 11 (4-6) 363-385.

Crosby, F.J. (1982). Relative Deprivation and Working Women.

New York: Oxford.

Deaux, K., \& Major, B. (1987). Putting gender into context: An

interactive model of gender-related behavior.

Psychological Review, 94 (3), 369-89.

Dion, K. (1985). Socialization in adulthood. in G. Lindzey \& E.

Aronson (Eds.), Handbook on Social Psychology, Vol II, (3rd

Ed.). New York: Random House.

Dohrenwend, B.P., \& Shrout, P.E. (1984). "Hassels" in the

conceptualization and measurement of life stress.

American Psychologist, 40, 780-785.

Drake, B. H. (1986). Communicating influence attempts in

dyads: Linguistic sedatives and palliatives. Academy of

Management Review, 11 (3), 567-84.

Duffy, S. M., \& Rusbult, C. E. (1986). Satisfaction and

commitment in homosexual and heterosexual relationships.

Journal of Homosexuality, 12 (2), 1-23. 
Eagly, A. H. (1987). Sex Differences in Social Behavior.

Hillsdale, NJ: Erlbaum.

Erdwins, C., \& Mellinger, J. C. (1986). Reentry women after graduation. Journal of Genetic Psychology, 147 (4), 437446.

Falbo, T. (1977). Multidimensional scaling of power strategies. Journal of Personality and Social Psychology, 35, 537-47.

Felton, B.J., Revenson, T.R., \& Hinrichson, G.A. (1984). Stress and coping in the explanation of psychological adjustment among chronically ill adults. Social Science and Medicine, 18, 889-898.

Fincham, F., \& Bradbury, T. (1987). The assessment of marital quality: A re-evaluation. Journal of Marriage and the Family, 49, 797-809.

Firestein, Beth Ann. (1987).The relationship of abuse and social support to the psychological health of college women in dating relationships. Invited address: Outstanding student research award. Annual Meeting of the Association for Women in Psychology, Newport, Rhode Island, 1988.

Forsyth, D. R., Schlenker, B. R., Leary, M. R., \& McCown, N. E.

(1985). Self-presentational determinants of sex differences in leadership behavior. Small Group Behavior, 16 (2), 197-210.

Fowers, B.J. (1991). His and her Mariage: A multivariate study of gender and marital satisfaction. Sex Roles, 24, 209-221. Fleischer, R.A., \& Chertkoff,J.M. (1986). Effects of dominance and sex on leader selection in dyadic work groups. Journal of Personality and Social Psychology, 43, 915-928.

Freilino, M. K., \& Hummel, R. (1985). Achievement and identity in college-age vs. adult women students. Journal of Youth and Adolescence, 14 (1), 1-10.

French, J.R., \& Raven, B. (1959). The Bases of Social Power. In D. Cartwright (Ed.), Studies in Social Power. (pp.150-167). Ann Arbor, MI: University of Michigan Institute for Social Research. 
Frieze, I. H. (1983). Investigating the Causes and Consequences of Marital Rape. Signs: Journal of Women in Culture and Society, 8 (3), 533-553.

Gaelick, L., Bodenhasuen, G. V., \& Wyer, R. S. (1985). Emotional Communication In Close Relationships. Journal of Personality and Social Psychology, 49 (5), 1246-1265.

Geis, F. L., Boston, M. B., \& Hoffman, N. (1985). Sex of authority role models and achievement by men and women:

Leadership performance and recognition. Journal of Personality and Social Psychology, 49 (3), 636-653.

Gerber, G.L. (1991). Gender stereotypes and power: Perceptions of the roles in violent marriages. Sex Roles, 24, 439-457.

Gerson, J. M. (1985). Women returning to school: The consequences of multiple roles. Sex Roles, 13 (1-2), 77-92. Gilbert, L.A., Dancer, S., Rossman, K. M., and Thorn, B.L. (1991). Assessing perceptions of occupational-family integration. Sex Roles, 24, 107-119.

Gilligan, C. (1979). Woman's place in man's life cycle. Harvard Educational Review, 49 (4), 431-46.

Goode, W. J. (1960). A theory of role strain. American Sociological Review, 1960, 25, 483-496.

Gottman, J.M. and Krokoff, Lowell J. (1989). Marital interaction and satisfaction: A longitudinal view. Journal of Consulting and Clinical Psychology, 57, 47-52.

Gove, W.R. (1972).The relationship between sex roles, mental illness and marital status. Social Forces, 51, 31-44.

Grauerholz, E., \& Serpe, R. (1985). Initiation and response: The dynamics of sexual interaction. Sex Roles, 12 (9-10), 1041 59.

Gray-Little, B.,\& Burks, N. (1983). Power and satisfaction in marrige: A review and critique. Psychological Bulletin, 93 (3), 513-38.

Hansen, C., \& Morokoff, P. (1988, August). Marital influence strategies: Relationship to marital and sexual satisfaction. Paper presented at the Annual meeting of the American Psychological Association, Atlanta, GA. 
Henley, N. M. (1977). Body Politics: Power, Sex and Nonverbal

Communications. Englewood Cliffs, NJ: Prentice-Hall.

Hester, M. (1984). Anti-sexist men: A case of cloak and dagger chauvinism. Women Studies International Forum, 7 (1), 33-37.

Higgins, M. N. (1985). Crisis intervention for the "second time around" college female. Emotional First Aid: A Journal of Crisis Intervention, 2 (2), 5-8.

Hildreth, G. J., Dilworth-Anderson, P., \& Rabe, S. M. (1983).

Family and school life of women over age 50 who are in college. Educational Gerontology, 9 (4), 339-50.

Hirsch, B.J. and Rapkin, B.D. (1986). Multiple role, social networks, and women's well-being. Journal of Personality and Social Psychology, 51, 1237-1247.

Hoffman, L. W. (1977). Changes in family roles, socialiation, and sex differences. American Psychologist, 32(8), 644657.

Holiday, G. (1985). Addressing the concerns of returning women students. New Directions for Student Services, 29 (3), 61-73.

Holmes T.H., \& Rahe, R.H. (1967). The social readjustment rating scale. Journal of Psychosomatic Research, 11, 213-218.

Hooper, J. O. (1979). My wife, the student. The Family

Coordinator, 28 (4), 459-64.

Howard, J. A., Blumstein, P., \& Schwartz, P. (1986). Sex, power and influence tactics in intimate relationships. Journal of Personality and Social Psychology, 51 (2), 102-109. Huston, T.L. and Vangelisti, A.L. (1991). Socioemotional Behavior and Satisfaction in Marital Relationships: a Longitudinal Study. Journal of Personality and Social Psychology, 61, 721-733.

Huston-Homburg, L., \& Strange, C. (1985). Spouse support among male and female returning students. Journal of College Student Personnel, 27 (5), 388-394.

Johnson, P. (1976). Women and Power: Toward a Theory of Effectiveness. Journal of Social Issues, 32 (3), 99-110. 
Kahn, A. (1983). The power war. Psychology of Women Quarterly, 238-247.

Kale, W.L. \& Stenmark, D.E. (1983). A comparison of four life event scales. American Journal of Community Psychology, $11,441-458$.

Katzoff, R. G., \& Paff-Santoro, J. (1981, April). Adapting student services for the adult student- a peer counseling model, in M. Kent (Ed.), Praxis. Collection of papers presented at the Annual Conference of the Association of College UnionsInternational, San Francisco, CA.

Kipnis, D., Castell, M. G., \& Mauch, D. (1976). Metamorphic effects of power. Journal of Applied Pychology, 61 (2), 127-34.

Koss, M. P. (1985). The Hidden Rape Victim: Personality, attitudinal and situational characteristics. Psychology of Women Quarterly, 9, 193-212.

Koss, M. P., Leonard, K. E., Beesley, D. A., \& Oros, C. J. (1985). Nonstranger sexual aggression: A Discriminate Analysis of the psychological characteristics of undecteted offenders. Sex Roles, 12 (9-10), 981-992.

Kurdeck, L. A., \& Schmitt, J. P. (1986). Relationship quality of gay men in closed or open relationships. Journal of Homosexuality, 12 (2), 85-99.

Lewin, M. (1985). Unwanted intercourse: The difficulty of saying no. Psychology of Women Quarterly, 9, 184-92.

Lobel, S.A. (1991). Allocation of investment in work and family roles: Alternative theories and implications for research. Academy of Management Review, 16, 507-521.

Locke, H., \& Wallace, K. (1959). Short marital adjustment and prediction tests: Their reliability and validity. Marriage and Family Living, 21, 251-55.

Lott, B. (1985). The Devaluation of Women's Competence. Journal of Social Issues, 41 (4), 43-60.

Lott, B. (1987). Women 's Lives: Themes and Variations in Gender Learning. Monterey, CA: Brooks/Cole. 
Lynch, J. M., \& Reilly, M. E. (1986). Role relationships: Lesbian perspectives. Journal of Homosexuality, 12 (2), 53-69.

Malamuth, N. M. (1981). Rape Proclivity Among Males. Journal of Social Issues, 37(4), 138-57.

Maples, M.F. (1985). Dual career marriages: Elements for potential success. In B.A. Stead (Ed.), Woman in Management, 2nd Ed. Englewood Cliffs, N.J.: Prentice Hall. Markman, H. J. (1979). Application of a behavioral model of marriage in predicting relationship satisfaction of couples planning marriage. Journal of Consulting and Clinical Psychology, 47, 743-49.

Markman, H.J., Floyd, F.J., Stanley, S.M., and Storaasli, R.D. (1988). Prevention of Marital Distress: A longitudinal investigation. Journal of Consulting and Clinical Psychology, 56, 210-217.

Meers, B. W., \& Gilkison, B. (1985). Older students on campus. Journal of College Student Personnel, 26 (4), 369-370. Miller, J. B. (1976). Towards a New Psychology of Women. Boston: Beacon.

Mitchell, R.E., \& Moos, R.H. (1984). Deficiencies in social support among depressed patients: Antecedents or consequences of stress? Journal of Health and Social Behavior, 25, 438452.

Mohney, C., Anderson, W. (1988). The effect of life events and relationships on adult women's decisions to enroll in college. Journal of Counseling and Development, 66, 271274.

Morokoff, P. (1987, April). Marital control and the sexual relationship. Paper presented at the Eastern Region Society for the Scientific Study of Sex. Philadelphia, PA.

Nieva, V. F, \& Gutek, B. A. (1981). Women and Work. New York: Praeger Publishers.

Nye, F.I. (1974). Husband and wife relationships. In L.W. Hoffman and F.I. Nye, (Eds.), Working Mothers. San Francisco: Jossey-Bass, 1974. 
Nyquist, L. V., \& Spence, J. T. (1986). Effects of Dispositional Dominance and Sex Role Expectations on Leadership Behaviors. Journal of Personality and Social Psychology, $50(1)$, 87-93.

Olson, D. H., \& Rabunsky, C. (1972). Validity of four measures of family power. Joumal of Marriage and the Family, 34, 224-34.

On Campus With Women, Project on the Status of Women (1986). Association of American Colleges, Washington, DC. Orcutt, J. D., \& Harvey, L. K. (1985). Deviance, rule-breaking and male dominance in conversation. Symbolic Interaction, 8 (1), 15-32.

Ostrow, E., Paul, S.C., Dark, V.J. \& Behrman, J.A. (1986) Adjustment of women on campus, effects of stressful life events, social support and personal competencies. in S.E. Hobfoll (Ed.), Stress, Social Support and Women (p. 29-43). New York: Hemisphere.

Parker, M., Peltier, S, and Wolleat, P. (1985). Understanding dual career couples. in B.A. Stead (Ed.), Women in Management. 2nd. Ed. (pp 75-86). Englewood Cliffs, NJ: Prentice Hall.

Pearlin, L.I., Lieberman, M.A., Menaghan, E.G., \& Mullan, J.T. (1981). The structure of coping. Journal of Health and Social Behavior, 19, 2-21.

Peplau, L. A. (1979). Power in dating relationships. In J.

Freeman (Ed.), Women: A Feminist Perspective. (2nd ed.) Palo Alto, CA: Mayfield.

Peplau, L. A., Rubin, Z., \& Hill, C. T. (1977). Sexual intimacy in dating relationships. Journal of Social Issues, 33, 86-109. Pleck, J. H. (1979). Men's family work: Three perspectives and some new data. The Family Coordinator, 28 (4), 481-488.

Pond, D.A., Ryle, A., \& Hamilton, M. (1963). Marriage and neurosis in a working class population. British Journal of Psychiatry, 109, 592-598.

Quina, K. (1987). Feminist transformation of the Psychology curriculum. Currents, 5 (2), 54-62. 
Quina-Holland, K., \& Kanarian, M. (1983, March). The older woman in school: Research and intervention models. Paper presented at the annual meeting of the Association of Women in Psychology, Seatle, WA.

Rahe, R. \& Ransom, A.J. (1978). Life change and illness studies:

Past history and future directions. Journal of Human Stress, 3-15.

Raven, B. H., Centers, R., \& Rodrigues, A. (1975). The bases of conjugal Power. In R. E. Cromwell \& D. H. Olson (Eds.), Power in Families. New York: Wiley.

Reilly, M.E., \& Lynch, J.M. (1990). Power sharing in lesbian partnerships. Journal of Homosexuality, 19, 1-30.

Reiss, I. L., \& Lee, G. R. (1988). Family Systems in America.

New York: Holt, Rinehart \& Winston.

Richter, D.L., \& Witten, C.H. (1984). Barriers to adult learning:

Does anticipation match reality? Journal of College Student Personnel, 25 (5), 465-467.

Roach, A.J., Frazier, L.P., \& Bowden, S.R. (1981). The marital satisfaction scale: Development of a measure for intervention research. Journal of Marriage and the Family, $40,537-546$.

Roehl, J.E., \& Okien, M.A. (1984). Depression symptoms among women reentering college: The role of negative life events and family social support. Journal of College Student Personnel, 25 (3), 251-254.

Rosenthal, R. \& Rosnow, R. L. (1984). Essentials of Behavioral Research: Methods and Data Analysis. New York: McGrawHill.

Rush, F. (1978). The Best Kept Secret: Sexual Abuse of Children. Englewood Cliffs, NJ: Prentice Hall.

Safilios-Rothschild, C. (1977). Love, Sex and Sex Roles.

Englewood Cliffs, NJ: Prentice Hall.

Safilios-Rothschild, C. (1970). The study of family power structure: a review 1960-1969. Journal of Marriage and the Family, 539-552. 
Sands, R.G., \& Richardson, V. (1984). Educational and mental health factors associated with the return of mid-life women to school. Educational Gerontology, 10 (1/2), 155170.

Sarason, I.G., Johnson, J.H., \& Siegel, J.M. (1978). Assessing the impact of life changes: Development of the life experiences survey. Journal of Consulting and Clinical Psychology, 46, 932-946.

Sarason, I.G., Sarason, B.R., Potter, E.H., \& Antoni, M.H. (1985).

Life events, social support and illness. Psychomatic Medicine, 47, 156-163.

Scanzoni, J., \& Szinovacz, M. (1980). Family Decision making, Beverly Hills: Sage Publications.

Sewall, T. (1984). A study of adult undergraduates: What causes them to seek a degree? Journal of College Student Personnel, 25 (4), 309-314.

Slaney, F.M. (1986). Career indecision in reentry and undergrduate women. Journal of College Student Personnel, 27 (2), 114-19.

Sorbel, M. E., \& Bohrnstedt, G. W. (1985). Use of null models in evaluating the fit of covariance structure models (pp 152178). in N. B. Tuma (Ed.), Sociological Methodology. San Francisco: Jossey-Bass.

Sorbom, D., \& Joreskog, K. G. (1981). The use of LISREL in sociological model building (pp 179-199). in D. J. Jackson \& E. F. Borgatta (eds.), Factor Analysis and Measurement in Sociological Research. Beverly Hills, CA: Sage.

Spanier, G.B. (1976). Measuring dyadic adjustment: New scales for assessing the quality of marriage and similar dyads.

Journal of Marriage and the Family, 48, 15-28.

Speer, L. \& Dorfman, L. (1986). The outcomes of re-entry education: Personal and professonal development in middle-aged and older women graduates. Educational Gerontology, 12 (3), 253-65.

Spence, J.T., Deaux, K., \& Helmreich, Robert L. (1985). Sex Roles in Contemporary American Society, in G. Lindzey \& E. 
Aronson, (Eds.), Handbook of Social Psychology II, (3rd ed.). New York: Random House.

Sprecher, S. (1985). Sex differences in bases of power in dating relationships. Sex Roles, 12 (3/4), 449-462.

Steil, J.M. and Weltman, K. (1991). Marital inequality: The importance of resources, personal attributes, and social norms on career valuing and the allocation of domestic responsibilities. Sex Roles, 24, 161-179.

Szinovacz, M.E. (1987). In M. Sussman \& S. Steinmetz (Eds.), Handbook of Marriage and the Family (pp 651-693). New York: Plenum.

Terman, L. M. (1938). Psychological Factors in Marital Happiness. New York: McGraw-Hill.

Thoits, P.A. (1983).Multiple identities and psychological wellbeing. American Sociological Review, 48, 174-187.

Thibaut, J.W. \& Kelley, H.H. (1959). The Social Psychology of

Groups. New York: Wiley \& Sons.

Tausig, M. (1982). Measuring life events. Journal of Health and Social Behavior, 23, 52-64.

Vanfossen, B.E. (1986). Sex differences in depression: The role of spouse support. in S.E. Hobfoll (Ed.), Stress, Social

Support and Women (p. 69-83). New York: Hemisphere.

Vaux, A. and Harrison D. (1985). Support network

characteristics associated with support satisfaction and perceived support. American Journal of Community

Psychology, 13, 3, 245-253.

Vinokur, A., Schyl, Y., Caplan, R.D. (1987). Determinates of perceived social support: Interpersonal transactions, personal outlook, and transient affective states, Journal of Personality and Social Psychology, 53, 1137-1145.

Walker, L.E. (1979). The Battered Woman. New York: Harper \& Row.

Wallston, B.S., Alagna, S.W., DeVellis, B.M., \& DeVellis, R.F. (1983). Social support and physical health. Journal of Health and Social Behavior, 24, 30-46. 
Weedon, C. (1987), Feminist Practice and Post-structuralist

Theory. New York: Blackwell.

Westkott, M. (1979). Feminist Criticism of the Social Sciences.

Harvard Educational Review 49:4, 422-29.

Whisman, M. and Jacobson, N.S. (1989). Depression, marital satisfaction, and marital and personality measures of Sex Roles. Journal of Marital and Family Therapy. 15, 177-186. Wilcox, B.L. (1981). Social support, life stress, and psychological adjustment: A test of the buffereing hypothesis. American Journal of Community Psychology, 9, 371-386.

Wood, W. (1987). Meta-analytic review of sex differences in group performance. Psychological Bulletin, 102 (1), 53-71. Wood, W., \& Karten, S. J. (1986). Sex differences in interaction style as a product of inferred sex differences in competence. Journal of Personality and Social Psychology, $50,341-47$.

Zick, C. \& McCullough, J. L. (1991). Trends in married couples' time use: Evidence from 1977-78 and 1987-88. Sex Roles, $34,459-487$. 